\title{
Succession within the prokaryotic communities during the VAHINE mesocosms experiment in the New Caledonia lagoon
}

\author{
Ulrike Pfreundt $^{1}$, France Van Wambeke ${ }^{2}$, Mathieu Caffin ${ }^{2}$, Sophie Bonnet ${ }^{2,3}$, and Wolfgang R. Hess ${ }^{1}$ \\ ${ }^{1}$ Faculty of Biology, University of Freiburg, Schaenzlestr. 1, 79104 Freiburg, Germany \\ ${ }^{2}$ Aix Marseille Université, CNRS/INSU, Université de Toulon, IRD, Mediterranean Institute of Oceanography \\ (MIO) UM110, 13288 Marseille, France \\ ${ }^{3}$ Institute de Recherche pour la Développement (IRD) Nouméa, 101 Promenade R. Laroque, BPA5, 98848, \\ Nouméa CEDEX, New Caledonia
}

Correspondence to: Wolfgang R. Hess (wolfgang.hess@ biologie.uni-freiburg.de)

Received: 4 December 2015 - Published in Biogeosciences Discuss.: 18 December 2015

Revised: 31 March 2016 - Accepted: 11 April 2016 - Published: 21 April 2016

\begin{abstract}
N}_{2}$ fixation fuels $\sim 50 \%$ of new primary production in the oligotrophic South Pacific Ocean. The VAHINE experiment has been designed to track the fate of diazotrophderived nitrogen (DDN) and carbon within a coastal lagoon ecosystem in a comprehensive way. For this, large-volume $\left(\sim 50 \mathrm{~m}^{3}\right)$ mesocosms were deployed in the New Caledonian lagoon and were intentionally fertilized with dissolved inorganic phosphorus (DIP) to stimulate $\mathrm{N}_{2}$ fixation. This study examined the temporal dynamics of the prokaryotic community together with the evolution of biogeochemical parameters for 23 consecutive days in one of these mesocosms (M1) and in the Nouméa lagoon using MiSeq 16S rRNA gene sequencing and flow cytometry. Combining these methods allowed for inference of absolute cell numbers from $16 \mathrm{~S}$ data. We observed clear successions within M1, some of which were not mirrored in the lagoon. The dominating classes in M1 were Alpha- and Gammaproteobacteria, Cyanobacteria, eukaryotic microalgae, Marine Group II Euryarchaeota, Flavobacteriia, and Acidimicrobia. Enclosure led to significant changes in the M1 microbial community, probably initiated by the early decay of Synechococcus and diatoms. However, we did not detect a pronounced bottle effect with a copiotroph-dominated community. The fertilization with $\sim 0.8 \mu \mathrm{M}$ DIP on day 4 did not have directly observable effects on the overall community within M1, as the data samples obtained from before and 4 days after fertilization clustered together, but likely influenced the development of individual populations later on, like Defluviicoccusrelated bacteria and UCYN-C-type diazotrophic cyanobac-
\end{abstract}

teria (Cyanothece). Growth of UCYN-C led to among the highest $\mathrm{N}_{2}$-fixation rates ever measured in this region and enhanced growth of nearly all abundant heterotrophic groups in M1. We further show that different Rhodobacteraceae were the most efficient heterotrophs in the investigated system and we observed niche partitioning within the SAR86 clade. Whereas the location in- or outside the mesocosm had a significant effect on community composition, the temporal effect was significantly stronger and similar in both locations, suggesting that overarching abiotic factors were more influential than the enclosure. While temporal community changes were evident, prokaryotic diversity (Shannon index) only declined slightly from $\sim 6.5$ to 5.7 or 6.05 in the lagoon and M1, respectively, throughout the experiment, highlighting the importance of multiple and varying sources of organic matter maintaining competition.

\section{Introduction}

The Southwest Pacific Ocean is recognized as an area with one of the highest dinitrogen $\left(\mathrm{N}_{2}\right)$-fixation rates in the global ocean (Garcia et al., 2007; Luo et al., 2012). In this region, plankton taxa capable of $\mathrm{N}_{2}$ fixation $\left(\mathrm{N}_{2}\right.$-fixing or diazotrophic organisms) are very diverse (Moisander et al., 2010) and fuel up to $60 \%$ of primary production (Bonnet et al., 2015a), yet their interactions with surrounding planktonic communities are rarely studied. Within this vast oceanic region, most of the studies investigating coupling 
between phytoplankton and heterotrophic bacteria have targeted the Nouméa lagoon in New Caledonia. Phytoplankton and heterotrophic bacterial production (BP) shows seasonal patterns, with maxima in December and January and an annual BP representing 21 to $34 \%$ of primary production (Torréton et al., 2010). High $\mathrm{N}_{2}$-fixation rates are a recurrent feature in the Nouméa lagoon (Biegala and Raimbault, 2008; Garcia et al., 2007), and diazotroph-derived N (DDN) was shown to be significantly channeled through the heterotrophic bacterial compartment in this environment (Berthelot et al., 2015; Bonnet et al., 2015b). However, no information is available on the potential effects of this $\mathrm{N}_{2}$ fixation on bacterial successions.

The production and quality of varying sources of organic matter is expected to vary as blooms of diazotrophic organisms are transient events. Such variation is expected to influence not only biogeochemical fluxes but also the succession of different heterotrophic bacteria, according to their metabolic capabilities. Indeed, the importance of quality and quantity of dissolved organic matter (DOM) in structuring bacterioplankton communities has been well established (Alonso-Sáez and Gasol, 2007; Beier and de Albuquerque, 2015), by either comparing the continuum of trophic conditions in situ (West et al., 2008) or following phytoplankton blooms under natural (Teeling et al., 2012) or experimental (Lebaron et al., 2001) conditions. Since the 1970s, heterotrophic bacterial succession during phytoplankton blooms has been observed with culture-dependent techniques (Fukami et al., 1981a) and linked to the possible origin of DOM sources (release, lysis, sloppy feeding, degradation of phytoplankton detritus), DOM size (low- or high-molecular weight molecules), or quality (Biddanda and Pomeroy, 1988; Murray et al., 2007; Nagata, 2000; Riemann et al., 2000).

The VAHINE experiment (Bonnet et al., 2016) provided a unique opportunity to study the fate of DDN in the marine planktonic food web and the interactions between phytoplankton and heterotrophic bacteria by simultaneously addressing biogeochemical parameters, stocks, and fluxes, as well as biodiversity based on 16S rRNA gene sequencing and flow cytometry cell counts. Taking into account different $16 \mathrm{~S}$ copy numbers, we used the absolute cytometry cell counts for Synechococcus and Prochlorococcus to calculate a samplespecific cells count to $16 \mathrm{~S}$ ratio and infer cells $\mathrm{mL}^{-1}$ for all operational taxonomic units (OTUs) obtained from MiSeq sequencing.

After fertilization with dissolved inorganic phosphorus (DIP: $\sim 0.8 \mu \mathrm{mol} \mathrm{L}^{-1}$ ) on the evening of day 4 , to alleviate potential limitation often observed in the region (Moutin et al., 2008), two periods of about 10 days each (P1 and $\mathrm{P} 2$, see description in Sect. 2.1) were identified in terms of diazotroph succession. During the first period, diatomdiazotroph associations were dominating (Turk-Kubo et al., 2015 ) the diazotrophic community with $\mathrm{N}_{2}$-fixation rates decreasing from $17.9 \pm 2.5$ to $10.1 \pm 1.3 \mathrm{nmol} \mathrm{N} \mathrm{L}^{-1} \mathrm{~d}^{-1}$ (Bon- net et al., 2015b). Unicellular $\mathrm{N}_{2}$-fixing cyanobacteria of the UCYN-C type (Cyanothece-like) dominated the diazotroph community in the mesocosms during the second period, but they did not appear in Nouméa lagoon waters (Turk-Kubo et al., 2015). $\mathrm{N}_{2}$-fixation rates increased during days $15-23$ and reached $>60 \mathrm{nmolNL}^{-1} \mathrm{~d}^{-1}$, which is among the highest rates measured in marine waters (Bonnet et al., 2015b; Luo et al., 2012). These two periods corresponded to characteristic successions in phytoplankton taxa, chlorophyll stocks, primary production and $\mathrm{BP}$, discussed in detail in companion studies in this issue (Berthelot et al., 2015; Leblanc et al., 2016; Van Wambeke et al., 2015).

In this research paper, we focus on prokaryotic community dynamics and possible parallels between or successions among different groups of phytoplankton, heterotrophic bacteria, and $\mathrm{N}_{2}$-fixing organisms.

\section{Material and methods}

\subsection{Mesocosm description, sampling strategy, and stocks/fluxes analyses}

Three large mesocosms $\left(\sim 50 \mathrm{~m}^{3}\right)$ were deployed in the nutrient-poor waters of the Nouméa lagoon close to the Boulari passage $\left(22^{\circ} 29.073 \mathrm{~S}-166^{\circ} 26.205 \mathrm{E}\right), 28 \mathrm{~km}$ off the coast from 13 January to 4 February 2013. Details of the location, deployment, and sampling strategy are described in Bonnet et al. (2016). The three triplicate mesocosms were fertilized with $\sim 0.8 \mu \mathrm{M} \mathrm{KH_{2 }} \mathrm{PO}_{4}$ between day 4 and day 5 of the experiment to promote a diazotroph bloom. Samples were collected every morning at 07:00 over a period of 23 days from three selected depths $(1,6,12 \mathrm{~m})$ in each meso$\operatorname{cosm}(\mathrm{M} 1, \mathrm{M} 2$, and M3) and in surrounding waters (hereafter referred to as Nouméa lagoon waters). For sequencing of the microbial community and metatranscriptomics, only one of the mesocosms, together with the Nouméa lagoon as a control, was sampled. Further details regarding the sampling are given separately (Pfreundt et al., 2016; Van Wambeke et al., 2015).

Subsampling and analysis procedures for stocks and fluxes are not given in detail here as they were mainly used for statistical analyses (see Sect. 2.3), but they are described in full in companion papers from this issue: inorganic nutrients and chlorophyll $a$ (Chl) concentrations, DIP turnover time, $\mathrm{N}_{2}$-fixation rates, and primary production (PP) were analyzed according to procedures detailed in Berthelot et al. (2015). Synechococcus and Prochlorococcus cell numbers were counted by flow cytometry (Leblanc et al., 2016). Heterotrophic bacterioplankton abundances were also determined by flow cytometry and corresponded to the sum of cells with high and low nucleic acid content, discarding autotrophic cell counts (Van Wambeke et al., 2015). BP was determined by the ${ }^{3} \mathrm{H}$ leucine technique, and alkaline phosphatase activity (APA) was determined on the total frac- 
tion (i.e., unfiltered samples) using MUF-P substrate (Van Wambeke et al., 2015). Three periods of the experiment were defined. P0 was defined as days $2-4$, before DIP fertilization of the mesocosms. P1 (days 5-14) was characterized by DIP availability and correspondingly lower APA inside the mesocosms (Van Wambeke et al., 2015). P2 (days 1523) was characterized by increasing $\mathrm{Chl} a$ concentrations, $\mathrm{N}_{2}$-fixation rates, $\mathrm{PP}$, and BP inside the mesocosms as well as in the Nouméa lagoon, albeit to a lower extent. Further, APA increased steeply, corresponding to DIP becoming limiting in the mesocosms during P2 (Berthelot et al., 2015; Van Wambeke et al., 2015).

\subsection{S rRNA gene amplicon sequencing and OTU clustering}

DNA was extracted from seawater samples collected every 2 days at 1 and $12 \mathrm{~m}$ depth in M1 and in Nouméa lagoon waters. A volume of $10 \mathrm{~L}$ was pre-filtered through a $1 \mathrm{~mm}$ mesh to keep out large eukaryotes and filtered on $0.45 \mu \mathrm{m}$ pore size, $47 \mathrm{~mm}$ diameter polyethersulfone filters (Pall Supor), immersed in RNA resuspension buffer $(10 \mathrm{mM} \mathrm{NaAc}$ pH 5.2, $200 \mathrm{mM} \mathrm{D}(+)$-sucrose, $100 \mathrm{mM} \mathrm{NaCl}, 5 \mathrm{mM}$ EDTA) and snap frozen in liquid $\mathrm{N}_{2}$. Tubes with filters were vortexed, then agitated in a Precellys bead beater (Peqlab, Erlangen, Germany) $2 \times(2 \times 15 \mathrm{~s})$ at $6500 \mathrm{rpm}$ after adding $0.25 \mathrm{~mL}$ glass beads $(0.10-0.25 \mathrm{~mm}$, Retsch, Frimley, UK) and $1 \mathrm{~mL}$ PGTX (39.6 g phenol, $6.9 \mathrm{~mL}$ glycerol, $0.1 \mathrm{~g} 8$ hydroxyquinoline, $0.58 \mathrm{~g}$ EDTA, $0.8 \mathrm{~g}$ NaAc, $9.5 \mathrm{~g}$ guanidine thiocyanate, $4.6 \mathrm{~g}$ guanidine hydrochloride, $\mathrm{H}_{2} \mathrm{O}$ to $100 \mathrm{~mL}$; Pinto et al., 2009). RNA and DNA were extracted simultaneously by adding $0.7 \mathrm{~mL}$ chloroform, shaking vigorously, incubating at $24^{\circ} \mathrm{C}$ for $10 \mathrm{~min}$, and subsequent phase separating by centrifugation. RNA and DNA were retained in the aqueous phase, precipitated together, and stored at $-80^{\circ} \mathrm{C}$ for further use for metatranscriptomics analysis (Pfreundt et al., 2016) and $16 \mathrm{~S}$ tag sequencing. For the latter, $\sim 100 \mathrm{ng}$ of RNase-treated total DNA was sent to a commercial provider (LGC Genomics, Berlin, Germany) for amplicon sequencing with primer pair S-D-Bact-0341-b-S-17/S-D-Bact-0785a-A-21 (Klindworth et al., 2013), which targets bacteria and archaea. Briefly, 16S hypervariable regions 3-4 were amplified and the amplicons sequenced on a MiSeq (Illumina) sequencer, generating between 31466 and 749629 paired-end reads $(2 \times 300)$ per sample.

All bioinformatic steps were done using the USEARCH package and following the UPARSE pipeline (Edgar, 2013) unless mentioned otherwise. Briefly, lowest quality tails were truncated from all reads and the paired reads merged using the -fastq_mergepairs command and yielding between 25221 and 604457 reads of average length > 400 nt per sample. Merged reads were then quality filtered, reads shorter than $350 \mathrm{nt}$ discarded, and converted to FASTA. All FASTA files were concatenated for OTU clustering, with the following steps: dereplication at $100 \%$ identity and keeping infor- mation on the weight of each unique sequence, sorting of unique sequences by decreasing weight and discarding of singletons (weight $=1$ ), and clustering into OTUs with the -cluster_otus command using a maximum dissimilarity of $2 \%$. The last steps includes chimera filtering (Edgar, 2013). Finally, the merged reads from the different samples were mapped back onto the generated OTUs using VSEARCH v1.1.3 (Rognes et al., 2015) with at least $98 \%$ identity to create the final OTU table. For taxonomic classification of the OTUs, they were submitted to https://www.arb-silva.de/ngs/ and classified using the SILVA SSU taxonomy and database release SSU 119.1 (Quast et al., 2013). Cyanobacterial OTUs that SILVA had only classified to family level were manually curated by BLASTN searches of these OTUs against NCBI's nucleotide collection. If a hit with $>95 \%$ sequence identity was found, the genus of this classification was added to the OTU table. For all further use, relative OTU abundances in each sample were calculated.

\subsubsection{Inference of absolute cell numbers from 16S data and flow cytometry}

Absolute cell numbers were inferred from these relative OTU abundances in three steps. First, raw read counts per OTU were normalized to equal $16 \mathrm{~S}$ copy numbers ("16S-norm reads") using a manually curated table of $16 \mathrm{~S}$ copies per genome for all OTUs (Supplement). For OTUs with no available genome, an average copy number of all genomes from marine representatives of the next higher phylogenetic clade was used (for the detailed procedure see Supplement). Second, the cumulated raw reads for Synechococcus (Syn) and Prochlorococcus (Pro) were divided by the respective sum of Synechococcus and Prochlorococcus cytometric cell counts for each sample, producing a sample-specific ratio (16Snorm reads / cells $\mathrm{mL}^{-1}$ ). We used Syn and Pro, because flow cytometry is well established for them and we could expect them to be reasonably precise. This ratio was then used to calculate cells $\mathrm{mL}^{-1}$ for all OTUs by dividing their $16 \mathrm{~S}$ norm reads in each sample by the sample-specific ratio. We are aware that missing genomic information may lead to errors in this calculation. OTUs for which no 16S copy number could be estimated were set to 1 copy/genome.

\subsubsection{Calculation of diversity measures.}

The Shannon and Simpson indices as measures of diversity were calculated separately for M1 and Nouméa lagoon waters using the diversity function in the $\mathrm{R}$ package vegan (Oksanen et al., 2015).

\subsection{Multivariate statistics of 16S-abundance community data, samples, and environmental data}

Statistical tools were all used with relative 16S abundance data. A canonical correspondence analysis (CCA; XLSTATS Excel software) was used to test for significant effects of bio- 
geochemical parameters on variations in the bacterial $16 \mathrm{~S}$ derived community structure. These parameters were PP, BP, $\mathrm{Chl}$, APA, DIP, $\mathrm{N}_{2}$-fixation rates, particulate organic carbon concentrations (POC), and temperature $(T)$. CCA generates ordination axes which are linear combinations of the environmental variables that best explain microbial diversity composition data (Braak, 1986). The variables were the logtransformed biogeochemical stocks and fluxes, the objects were the 34 dominating OTUs in terms of abundance (expressed in relative OTU abundance), and the sites were sampling time and origin of the samples.

Non-metric multidimensional scaling (NMDS) was used to find the best display of differences in 16S-derived community structures. The full OTU table containing relative abundances of each OTU per sample, with samples as rows and species as columns, was used for unconstrained ordination with the R package vegan (Oksanen et al., 2015). Additionally, the same procedure was run with the subset tables containing only "heterotroph" OTUs (i.e., all that are not classified as Cyanobacteria or chloroplasts) or only "autotroph" OTUs (i.e., all classified as chloroplasts or Cyanobacteria without Melainabacteria). First, the abundances were standardized using Wisconsin double standardization, which divides abundances by the species maximum and then standardizes samples to equal totals. This converts abundances per species into relative values and therefore reduces the weight of dominant species and increases the weight of rare species. Then, Bray-Curtis distance matrices were computed and an NMDS ordination calculated using metaMDS. MetaMDS did not use any further transformations or standardizations. Assuming that samples of days 2-8, days 1016, and days 18-21 cluster together, ellipses were drawn using the standard error for each cluster in the ordination plot with a confidence limit of 0.95 . Like this, we could consider clusters with non-overlapping ellipses as significantly different from each other at a significance level $\alpha=0.05$. Permutational multivariate analysis of variance (PERMANOVA) was conducted using the adonis function in the $\mathrm{R}$ package vegan on the Bray-Curtis distance matrices described above. We tested the dependence of sample distances on the factors location (M1 or lagoon waters), depth (1 or $12 \mathrm{~m})$, and time (separation of samples into three phases: days $2-8,10-16$, and 18-21).

To test significance of higher Cyanothece (UCYN-C) 16S abundances in M1 during P2, we defined two groups, days 214 (P0/P1) and days 16-21 (P2), both in M1 and the lagoon, leading to four groups. We applied ANOVA and Tukey's honestly significant difference (HSD) test to see whether the means of these groups were significantly different. We found that P2 in M1 was significantly different from the other three groups (Tukey's HSD $p$ values $0.00002,0.00009,0.00003$ ) and that $\mathrm{P} 2$ in the lagoon was not significantly different from $\mathrm{P} 0 / \mathrm{P} 1$.

Pearson and Spearman rank correlations were performed in $\mathrm{R}$ using the rcorr function, which also calculates the sig- nificance of the derived correlation coefficients. A coefficient was defined as significant if $p \leq 0.05$.

\section{Results}

\subsection{Biogeochemical context}

Here, we present data on the prokaryotic community in M1 and the Nouméa lagoon from depths of 1 and $12 \mathrm{~m}$, which was close to the bottom of the mesocosm. As a foundation for understanding and discussing these data, selected biogeochemical parameters are shown in Fig. 1 for the corresponding sampling locations. On the evening of day 4, M1 was fertilized with $\sim 0.8 \mu \mathrm{M}$ DIP, leading to lower APA than in the lagoon until day 19, when APA in M1 increased steeply (Fig. 1c, d) and DIP turnover times dropped below initial levels (Van Wambeke et al., 2015). Of the three mesocosms, the here investigated M1 was the one with the lowest increase of Chl $a$ during P2, still reaching higher levels than in Nouméa lagoon waters, whereas PP in M1 did not exceed the values measured in the lagoon (Fig. 1a, b). BP exhibited two prominent peaks in M1 with a 4-fold and 2-fold increase, on day 4 and on day 21, and was otherwise close to values measured for Nouméa lagoon waters, only slightly exceeding them on most days after day 11 (Fig. 1e).

\subsection{Bacterial community based on 16S tag MiSeq sequencing}

\subsubsection{An overview}

We identified a total of 3600 OTUs belonging to bacteria, archaea, and chloroplasts using 16S rRNA gene sequencing data from all samples combined (17 samples from M1, 20 samples from the Nouméa lagoon; see Supplement). On this basis, Shannon and Simpson indices as measures for overall diversity were calculated. With values between 5.6 and 7 (Shannon) at both investigated depths over the 23-day experiment, diversity was relatively high. Values above 5 have been reported for the edge of the South Pacific gyre (Yin et al., 2013), but they are based on clone libraries, which might underestimate diversity. Over the course of the experiment we observed a slight decrease in diversity both in M1 and in the lagoon (Supplement Fig. S1).

Throughout results and discussion, we will use absolute abundances inferred from 16S sequencing data and flow cytometry counts for Synechococcus and Prochlorococcus (see methods Sect. 2.2 and Supplement). The temporal evolution of relative (16S) and absolute (flow cytometry) Synechococcus abundances in M1 diverged substantially after day 4 (compare Figs. S4f and 2a). As Synechococcus and Prochlorococcus together constituted up to $30 \%$ of all $16 \mathrm{~S}$ reads, changes in absolute cell counts for these groups can highly influence the temporal evolution of relative $16 \mathrm{~S}$ data. To elude possible ambiguous interpretation of these data, 

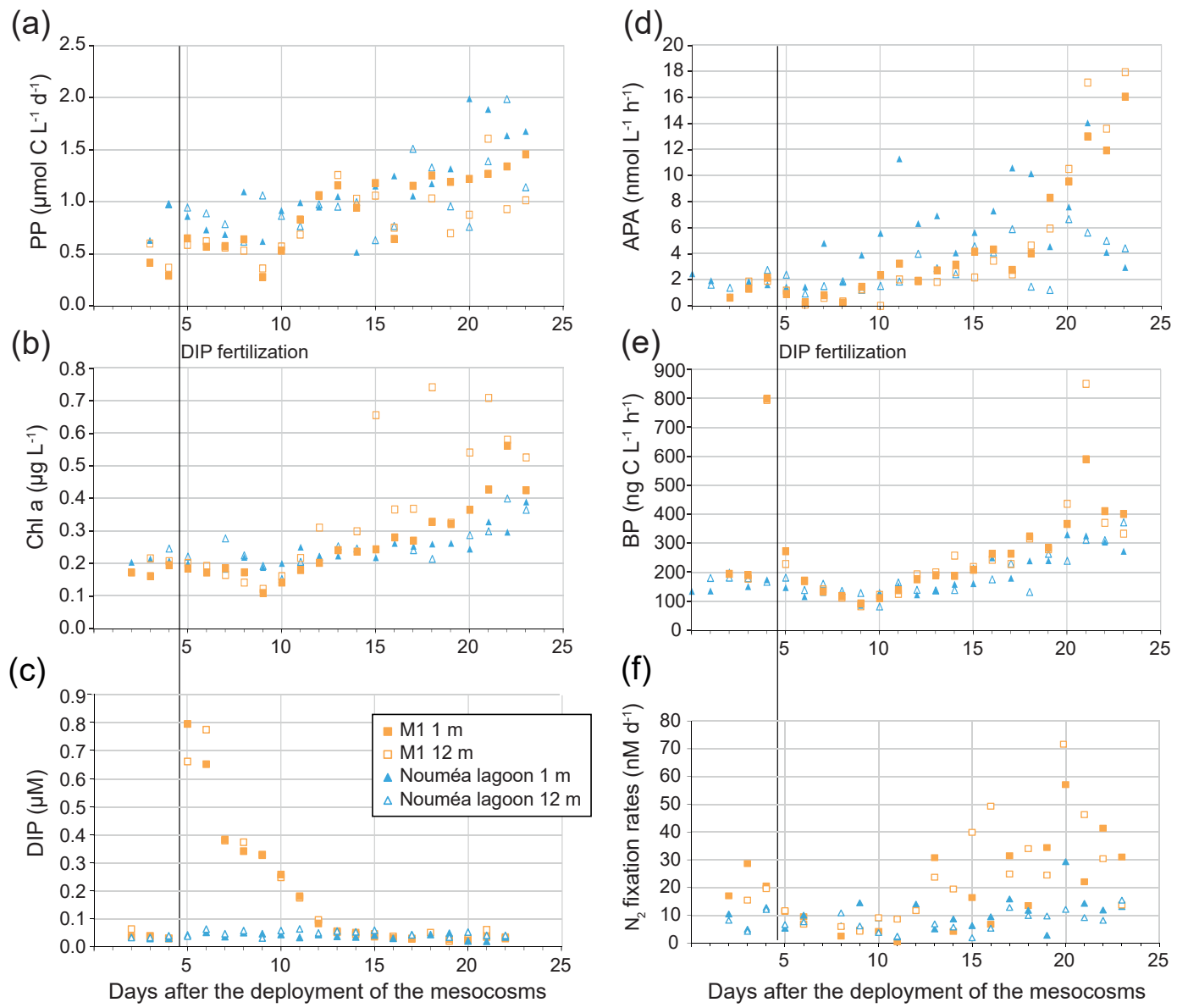

Figure 1. Evolution of selected parameters in mesocosm M1 and the Nouméa lagoon at depths of 1 and 12 m. (a) Primary production (PP), (b) chlorophyll $a(\mathrm{Chl} a)$ concentration, (c) dissolved inorganic phosphorous (DIP), (d) alkaline phosphatase activity (APA), (e) heterotrophic bacterial production (BP, measured by $3 \mathrm{H}$-leucine assimilation), and (f) $\mathrm{N}_{2}$-fixation rates as measured by ${ }^{15} \mathrm{~N}$ incorporation in $\mathrm{M} 1$ and the Nouméa lagoon.

we used the combined Synechococcus and Prochlorococcus cytometric counts to calculate a " $16 \mathrm{~S} /$ cells $\mathrm{mL}^{-1}$ " ratio for each sample (see Sect. 2.2). This ratio was then used to calculate absolute cell numbers from relative $16 \mathrm{~S}$ abundance in M1 for all other groups investigated here (Figs. 3, 4). Different $16 \mathrm{~S}$ copy numbers per genome for different OTUs/phylogenetic groups were taken into account (Supplement). We hope that this combinatorial approach using $16 \mathrm{~S}$ sequencing, flow cytometry, and 16S copies/genome may serve as a blueprint for future 16S-based studies. In the following, the term "16S community" will be used for the total inferred cell count per sample.

The dominating classes in M1 were Alpha- and Gammaproteobacteria, Cyanobacteria, chloroplasts, Marine Group II (MGII) Euryarchaeota (Thermoplasmata), Acidimicrobia, and Flavobacteriia (Fig. 3a). Of these, Alpha- and Gammaproteobacteria exhibited clearly different dynamics between M1 and the lagoon with completely different peaking times, whereas cyanobacteria, chloroplasts, MGII
Euryarchaeota, and Flavobacteriia showed similar trends (Figs. 3, 4, correlations in Fig. S2a). Amongst the classes contributing less than $5 \%$ to the total $16 \mathrm{~S}$ community, dynamics were generally different between M1 and the lagoon (Fig. S2b). Inside M1, Deferribacteres (almost entirely the SAR406 clade) and Deltaproteobacteria abundances halved after the DIP fertilization and increased again when DIP concentrations fell below $0.1 \mathrm{nM}$ on day 12 (Fig. 3c). All other groups increased at similar times, except for Actinobacteria, which responded later (Fig. 3b). Except for the increase in Flavobacteriia and Cyanobacteria (predominantly Synechococcus), none of these late-phase increases were observed in the lagoon (Fig. 4), although several of the less abundant classes (Cytophaga, Betaproteobacteria, Actinobacteria) more than doubled from day 16 to 18 in the lagoon but decreased just as quickly after that (Fig. 4b). 

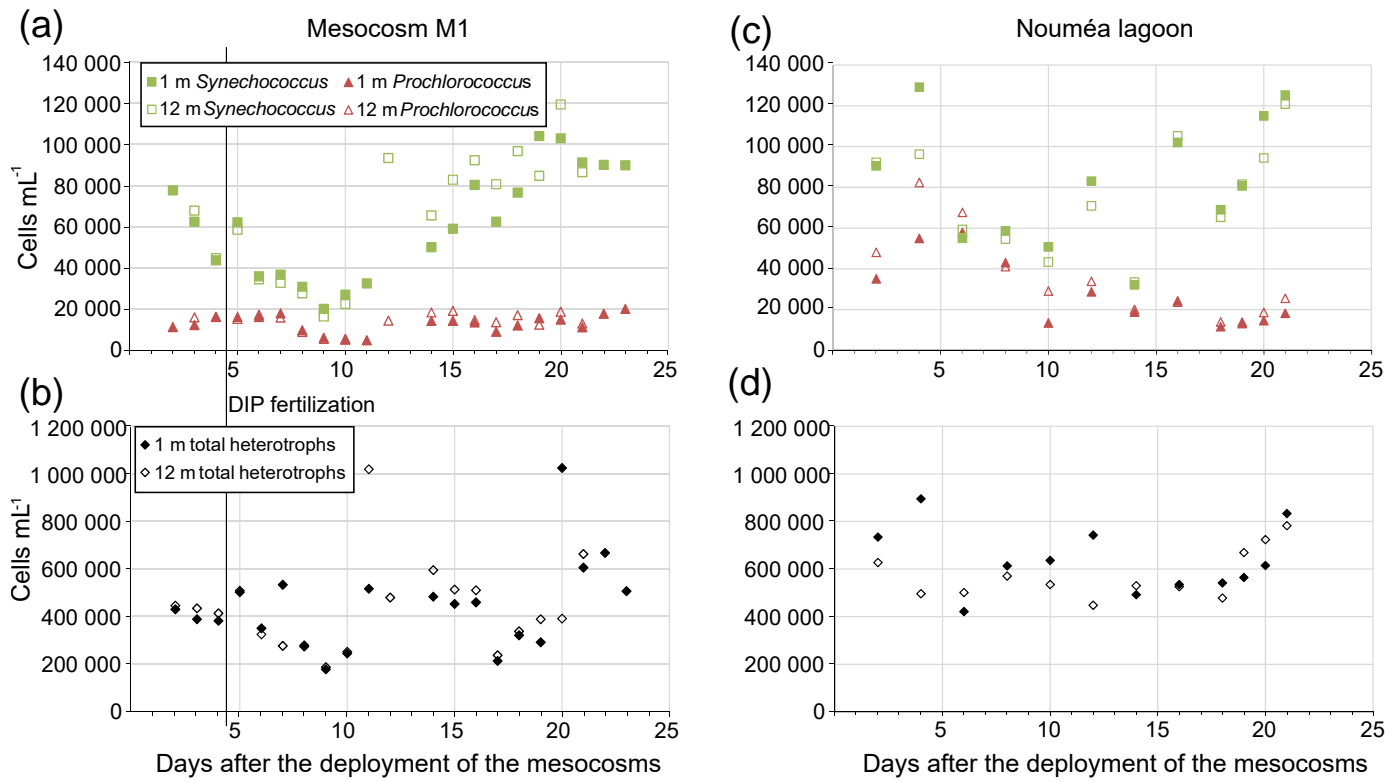

\section{(d)}

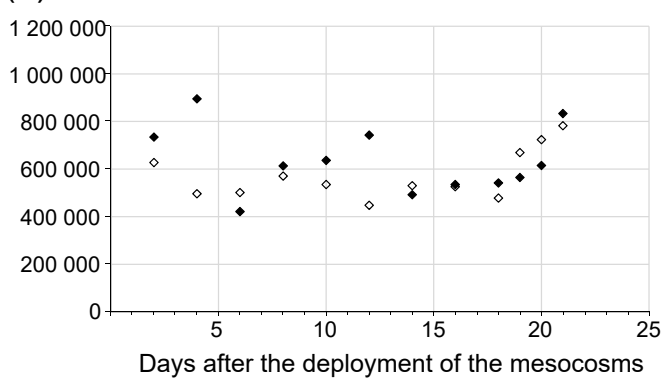

Figure 2. Evolution of absolute abundances as counted by flow cytometry at depths of 1 and $12 \mathrm{~m}$ of Synechococcus and Prochlorococcus in M1 (a) and the lagoon (c); evolution of non-photosynthetic bacteria (total heterotrophs) in M1 (b) and the lagoon (d).

\subsubsection{Cyanobacteria}

Synechococcus sp. (OTU-9) was the dominant OTU throughout the experiment in M1 and the lagoon, being almost an order of magnitude more abundant than the second ranked OTU at some time points. The steep drop of Synechococcus abundance on day 4 in M1, 2 days after the mesocosm closure, was equally seen in absolute counts by flow cytometry (from $\sim 78000$ to $\sim 44000$ cells mL ${ }^{-1}$; Fig. $2 \mathrm{a}$ ) and in the relative $16 \mathrm{~S}$ data (Fig. S4f). Please note that the inferred absolute abundances shown in Figs. $3 \mathrm{f}$ and $4 \mathrm{f}$ are not the same as the flow cytometry counts for Syn and Pro. We used the sum of Syn and Pro to infer the sample-specific ratios for the calculation to reduce putative counting biases in one of the two groups (see discussion). Inferred cell counts for Synechococcus were only 61000 and 25000 cells mL $\mathrm{mL}^{-1}$ for these 2 days. At the same time in M1, Prochlorococcus inferred abundance reached a maximum of 37000 cells $\mathrm{mL}^{-1}$ on day 6 , corresponding to $\sim 16000$ cells $\mathrm{mL}^{-1}$ counted with flow cytometry (Figs. 2a and 3f). Variations in Synechococcus abundance correlated with changes in Chl concentrations, except for days 2-5 with high Synechococcus cell counts but low Chl concentrations (Figs. 1b, 2a). $\mathrm{N}_{2}$-fixing cyanobacteria were generally 1 to 2 orders of magnitude less abundant than Prochlorococcus and Synechococcus and were in M1 most prevalent on days $2-4$, owing mainly to Trichodesmium with $\sim 5000$ cells $\mathrm{mL}^{-1}$ (Fig. 3f). After the DIP fertilization, Trichodesmium 16S tags dropped quickly by a factor of 10, leaving Calothrix as the most abundant diazotroph until day 12. Important to mention, the SILVA database used for $16 \mathrm{~S}$ classification lists all Richelia intracellularis $16 \mathrm{~S}$ se- quences as descendants of the Calothrix node. This is discussed in Sect. 4. Candidatus Atelocyanobacterium thalassa (UCYN-A) constituted the third most abundant diazotroph until day 14. UCYN-A may be seen as a heterotrophic diazotroph, as it misses photosystem II, cannot fix $\mathrm{CO}_{2}$ into biomass (Tripp et al., 2010), and lives in symbiosis with unicellular algae (Thompson et al., 2012). Between days 14 and 16, Cyanothece (UCYN-C) 16S tags increased by an order of magnitude, exhibiting significantly higher levels in M1 during $\mathrm{P} 2$ than during P0/P1 and in the lagoon (ANOVA followed by Tukey's HSD test, all $p$ values $<0.0001$ ). UCYN$\mathrm{C}$ was the most abundant diazotroph on day 16 in M1 with $\sim 400$ cells $\mathrm{mL}^{-1}$ (Fig. 3f). Heterotrophic diazotrophs like Bradyrhizobium and Mesorhizobium were, with a maximum of $0.00013 \%$ of the community for the former, not present in numbers anywhere close to $\mathrm{N}_{2}$-fixing cyanobacteria (Supplement). In the lagoon samples, the two dominant diazotrophs (Trichodesmium and Calothrix/Richelia) were the same but with different dynamics (Fig. 4f). Notably, Cyanothece (UCYN-C) OTUs did not increase in abundance in the lagoon.

\subsubsection{Heterotrophic bacteria}

As alpha- and gammaproteobacterial 16S abundances showed close to zero correlation between M1 and the lagoon (Fig. S2a), we examined the dynamics within these classes at family level. We observed clear successions within M1 that were not mirrored in the lagoon (Figs. 3c, d and $4 \mathrm{c}, \mathrm{d}$ ). On day 4 (2 days after the mesocosms had been closed around the water column), Rhodobacteraceae increased from $<10000$ to almost 35000 cells $\mathrm{mL}^{-1}$ in M1, 

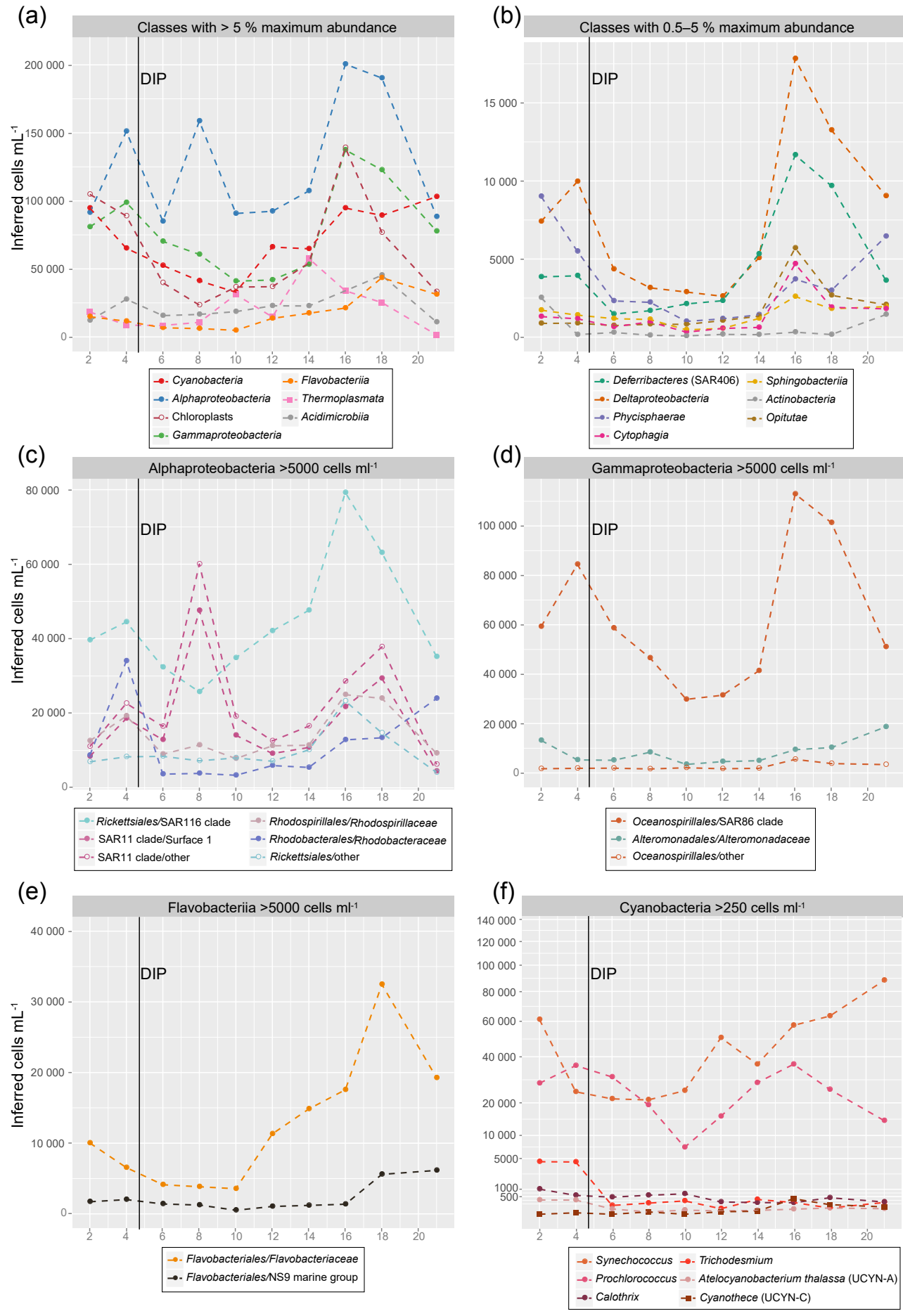

Days after the deployment of the mesocosms

Figure 3. Evolution of the $16 \mathrm{~S}$ community with time for surface samples $(1 \mathrm{~m}$ depth) inside mesocosm M1. Absolute abundances in cells $\mathrm{mL}^{-1}$ were inferred in three calculation steps. Initially, raw read counts per OTU were normalized to equal $16 \mathrm{~S}$ copy numbers ("16S-norm reads"). These reads were summed for all Prochlorococcus (Pro) and Synechococcus (Syn) OTUs in each sample and divided by the sum of flow cytometry cell counts for Syn and Pro in that sample, creating a ratio. For each OTU, the 16S-norm read count was then divided by this ratio to produce the inferred absolute abundance of that OTU. This procedure accounts for library size in each sample. For better visualization, the classes with (a) a maximum abundance above $5 \%$ and (b) a maximum abundance between 0.5 and $5 \%$ were plotted separately. (c-e) Families with $>5000$ cells $\mathrm{mL}^{-1}$ (at their respective maximum) amongst the dominant non-photosynthetic classes

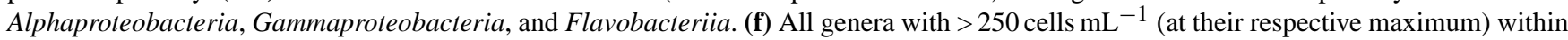
photosynthetic Cyanobacteria. Dashed lines were used to connect the data points for visualization purposes only. The DIP fertilization event in the evening of day 4 is indicated by a black vertical line. 


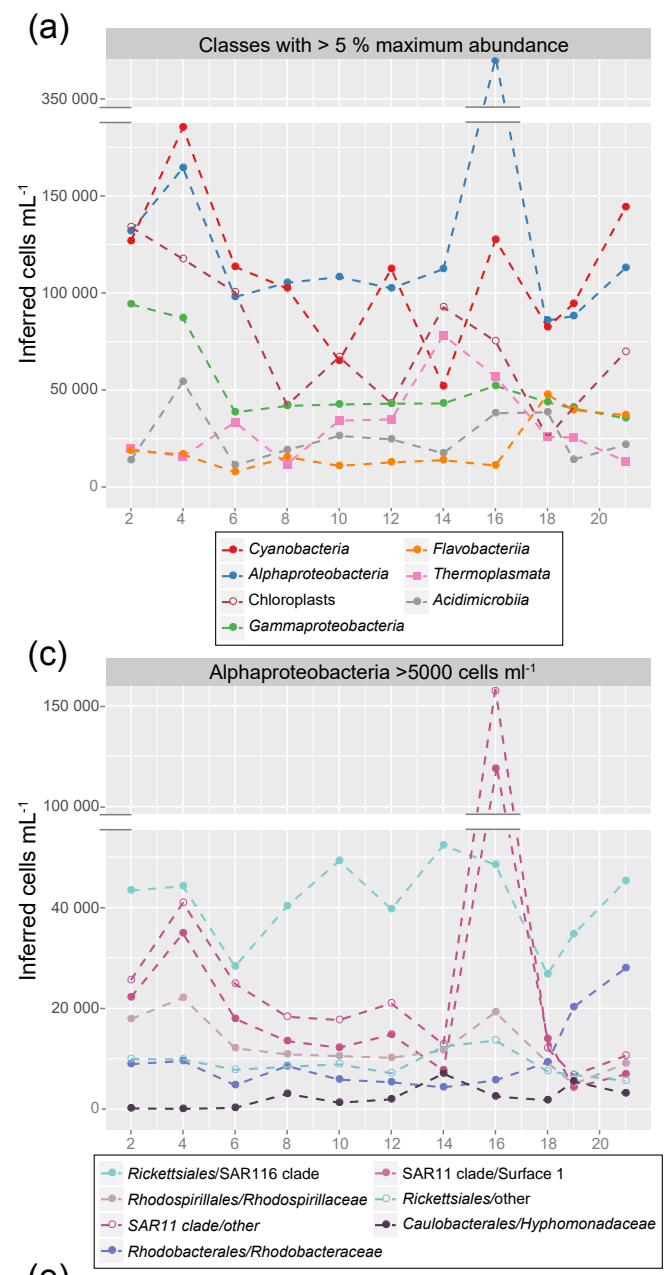

(b)
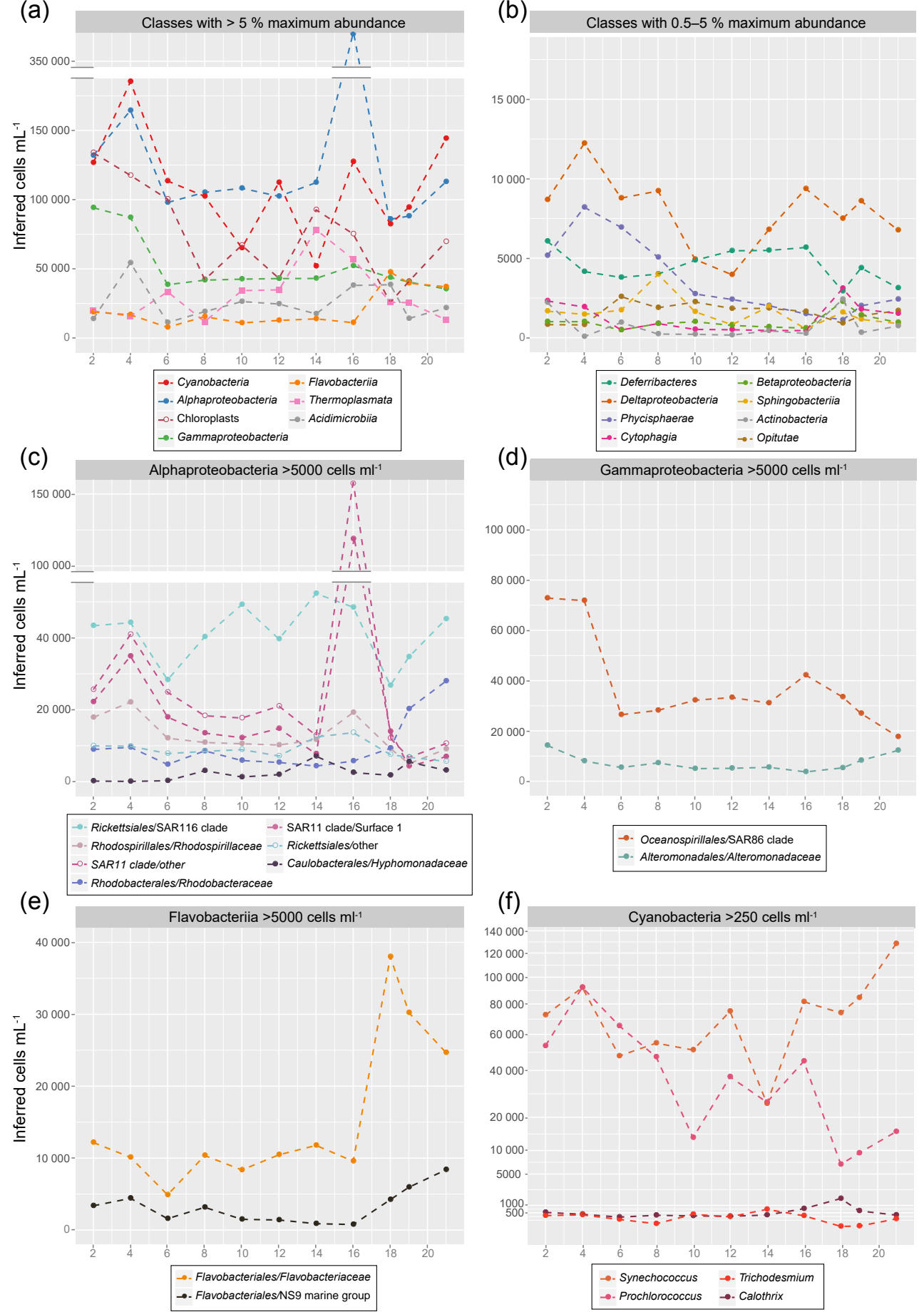

Days after the deployment of the mesocosms

Figure 4. Evolution of the $16 \mathrm{~S}$ community with time for surface samples in the Nouméa lagoon waters. All abundances are given as inferred absolute abundances in cells $\mathrm{mL}^{-1}$ as described for Fig. 3. Data were plotted in the same way as for Fig. 3.

and dropped (Fig. 3c). One particular OTU (297), classified as Thalassobium sp., contributed $79 \%$ of Rhodobacteraceae sequences on that day, but only $2-20 \%$ in other samples. This peak corresponded to increased transcript ac- cumulation from Rhodobacteraceae seen in the metatranscriptome analysis (Pfreundt et al., 2016) and a 4-fold increase in bacterial production on that day (Fig. 1e). This situation occurred the morning before the DIP fertilization 
and was accompanied by a $30-50 \%$ increase in SAR86, SAR11, and Rhodospirillaceae. Notably, a similar increase of SAR11 was observed in the lagoon (Fig. 4c), speaking against a M1-specific trigger for this group. In addition, a M1-specific severe drop of Synechococcus from $>60000$ to 25000 cells $\mathrm{mL}^{-1}$ was observed (Fig. 3f). While Rhodobacteraceae dropped to $\sim 5000$ cells $\mathrm{mL}^{-1}$ on day $6-$ similar to lagoon values - and stayed fairly stable until day 14, SAR11, dominated by the Surface 1 group, increased from 30000 to $>100000$ cells $\mathrm{mL}^{-1}$ on day 8 and outcompeted all other heterotrophic bacteria in M1 (Fig. 3c). SAR11 was replaced by SAR116 2 days later, the most numerous alphaproteobacteria for most of the experiment, and surpassed in numbers only by SAR86 at the end of the experiment (Fig. 3d). After day 14, Rhodobacteraceae other than Thalassobium became more numerous again both in M1 and the lagoon (Figs. 3c, $4 c)$.

Within Alphaproteobacteria, SAR11 abundance dynamics were completely uncorrelated between M1 and the lagoon, whereas other groups were slightly positively correlated (Fig. S2c). Within Gammaproteobacteria, Alteromonadaceae and SAR86 together constituted between 75 and almost $90 \%$ (Fig. 3d) and whereas the former showed very similar dynamics between M1 and the lagoon waters, SAR86 did not (Fig. S2d). A second abundance peak of SAR86 occurred only in M1 on days 16 and 18 and coincided with similar peaks of less abundant heterotrophic classes (Fig. 3b, d). While in M1, SAR86 never decreased below 30000 cells $\mathrm{mL}^{-1}$ with peaks of 80000 and 110000 cells $\mathrm{mL}^{-1}$, these bacteria were mostly around or below 30000 cells $\mathrm{mL}^{-1}$ in the lagoon after day 4 .

Within Flavobacteriia, the dominant families exhibited highly correlated temporal dynamics in M1 and the lagoon and also between the different families (Fig. S2e). The Flavobacteriaceae family dominated, increasing from 4000 to 32500 cells $\mathrm{mL}^{-1}$ between days 10 and 18 in M1 (Fig. 3e), in the period of DIP consumption, coinciding with higher $\mathrm{Chl}$ concentrations from day 12 onward (Fig. 1b, c). A maximum abundance of 38000 cells $\mathrm{mL}^{-1}$ was reached in the lagoon also on day 18 (Fig. 4e). The NS9 marine group, the second most abundant flavobacterial group, had very low abundances until day 16 and increased towards the end of the experiment in both locations.

Generally, a steep increase (>2-fold) of total nonphotosynthetic cells (abundant classes except Cyanobacteria and chloroplasts) from day 12 to day 16 was seen in M1 (Fig. 3a, b), which was not seen in flow cytometry counts of total heterotrophic bacteria (Fig. 2b) but was accompanied by a moderate increase (50\%) in BP (Fig. 1e), supporting the former. Spearman rank correlation between BP and inferred cell counts for non-photosynthetic bacteria was $0.56, p=0.09(0.72, p=0.03$ when omitting day 21 with its prominent $\mathrm{BP}$ peak). $\mathrm{N}_{2}$-fixation rates were also substantially higher throughout this period (days 12 to 16 ) than before and stayed high until the end of the experiment on day
23 (Fig. 1f). Preceding and overlapping this reaction of heterotrophs was a constant increase in Synechococcus from its minimum of $\sim 20000$ cells $\mathrm{mL}^{-1}$ on day 9 to maximally 104000 cells $\mathrm{mL}^{-1}$ on days 19-20 (Fig. 2a).

\subsubsection{Temporal dynamics of the $16 \mathrm{~S}$ community}

Using all OTUs as a basis, we did unconstrained ordination of all samples on Bray-Curtis dissimilarities calculated from standardized relative abundances. NMDS showed that inside M1 as well as in lagoon waters, the microbial communities defined three distinct clusters (Fig. 5a). Days 2-8, days 10 16, and days 18-21 (the last day 16S rRNA gene sequencing was done for) were grouped together and the clusters separated along the first MDS axis both in lagoon waters and in M1, whereas the locations lagoon waters and M1 (colorcoded in blue and orange, respectively) were also clearly separated along the second MDS axis. These clusters in time will be called early, mid-time, and late from here on and were time delayed from the periods $\mathrm{P} 0, \mathrm{P} 1$, and $\mathrm{P} 2$ defined by biogeochemical parameters, production rates, and $\mathrm{N}_{2}$ fixation (see Sect. 2.1). Thus, communities from M1 and the lagoon were clearly different from each other but followed a similar trajectory with time. When we separated the autotrophic community (547 OTUs) from the heterotrophic community (2981 OTUs, all OTUs other than cyanobacteria and chloroplasts) for ordination, it became evident that the heterotrophs showed a pattern very similar to the full community (Fig. 5b). The autotrophic community also clearly separated early, midtime, and late phases from each other in M1 and the lagoon, but not as far, and separation by location (M1 vs. lagoon waters) only really became evident in the late phase (Fig. 5c). PERMANOVA showed that indeed the community structures of the full OTU set, as well as both separate OTU sets, were significantly different between the three phases (predictor time) and were also different according to their origin, M1, or lagoon waters (predictor location; $p$ values $<0.001$, for autotrophs $p=0.003$ ). Using the interaction of the predictor location with time additionally showed that time still had a significant effect after taking out the location effect but not the other way around. This shows that the effect of time was stronger and included the effect of location. Depth had no significant effect.

\subsubsection{Effect of hydrological and biogeochemical parameters on the community structure of dominant OTUs}

The 34 dominant OTUs (in terms of summed relative abundances of all samples) were subjected to constrained ordination within the frame of eight environmental variables (BP, $\mathrm{PP}, \mathrm{APA}, \mathrm{Chl}, \mathrm{POC}, \mathrm{N}_{2}$ fixation, DIP, and temperature $T$ ), taking all samples from M1 and the lagoon from 1 and $12 \mathrm{~m}$ depth into account (Fig. 6). The sum of all unconstrained eigenvalues was 0.304 and the sum of canonical eigenvalues 

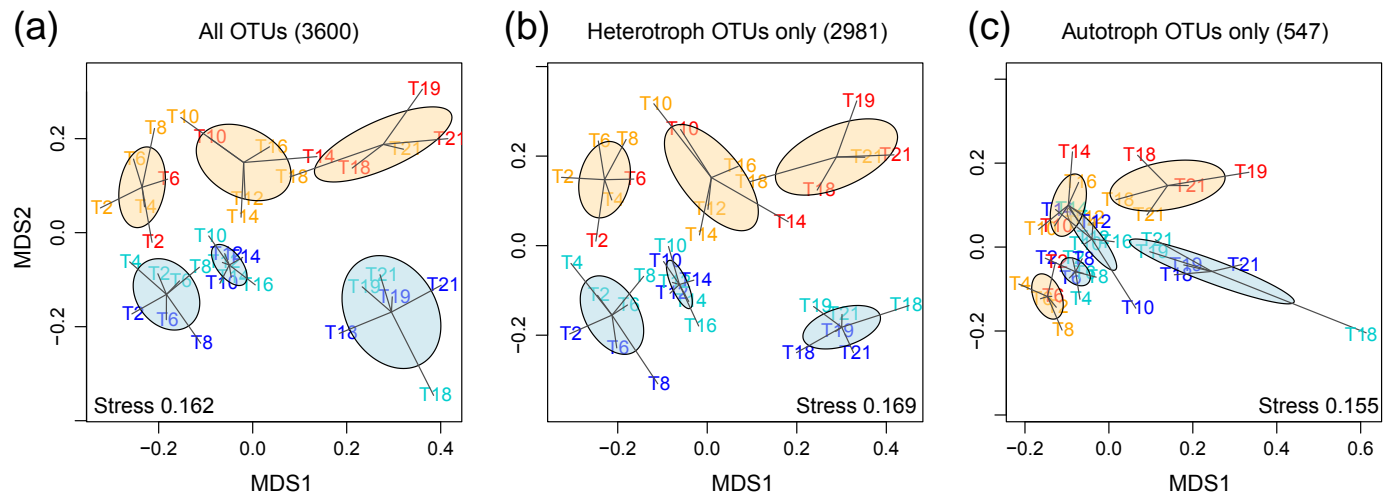

Figure 5. NMDS ordination of all samples using Bray-Curtis distances based on the relative abundances of (a) all OTUs, (b) only noncyanobacterial OTUs ("heterotrophic bacteria"), or (c) only OTUs classified as photosynthetic cyanobacteria. The samples are color-coded as follows: orange for the M1 surface, red for M1 $12 \mathrm{~m}$, light blue for the Nouméa lagoon surface, and blue for Nouméa lagoon $12 \mathrm{~m}$. Ellipses are color-coded in a similar way to distinguish M1 sample clusters and Nouméa lagoon sample clusters. Ellipses denote a confidence interval of 0.95 around the weighted average of each cluster. Thus, clusters can be considered significantly different with $\alpha=0.05$, if ellipses do not overlap.

was 0.130 . Thus, the amount of total variation in the species data that could be explained by the employed environmental variables was $43 \%$ (permutation test; $p<0.001$ after 999 permutations). The canonical axes F1 and F2 accounted for 50.5 and $22.3 \%$ of this total explainable variance and 21.6 and $9.5 \%$ of the total variance, respectively. Both axes were significant and displayed strong species-environment correlations ( $p<0.001$ for both axes). Samples (location and time; Fig. 6b) were mainly separated along F1 with days 6 to 14 towards negative values and days 16 to 21 towards positive values. Interestingly, samples from M1 were separated further apart from each other than those from the lagoon. The main parameters separating samples and OTUs (Fig. 6a) along the F1 axis were DIP, which was clearly higher in M1 samples following the DIP fertilization (days 6-10), and BP, $\mathrm{Chl}$, and PP in opposition to DIP. Highly associated with BP and $\mathrm{Chl}$ were the late-phase samples from M1 and lagoon, together with Rhodobacteraceae OTUs 1 and 37 and the flavobacterial NS4 marine group OTU 44, suggesting these directly profited from primary producers at the end of the experiment. Interestingly, another Rhodobacteraceae OTU (23) was tightly associated with $\mathrm{N}_{2}$ fixation and with the OM60(NOR5) OTUs 2 and 18 from the Halieaceae family of Gammaproteobacteria. Other gammaproteobacterial OTUs, Alteromonas OTU 13 and SAR86 OTUs 7 and 26, were positioned oppositely, closer to high DIP values, and together with all three SAR11 OTUs $(43,60,2922)$, three of four SAR116 OTUs $(16,20,34)$, the Rickettsiales group S25(593) OTU 27, and Candidatus Actinomarina OTU 6 (Actinobacteria). Most tightly associated with high DIP concentrations was Defluviicoccus OTU 40 (Rhodospirillaceae). Also in the same quadrant, but forming a separate cluster, were MGII Euryarchaeota. Two more SAR86 OTUs $(98,1229)$ were separated from the rest and linked with Prochlorococcus and with the very early samples from days 2 to 4 in M1 and days 2 to 8 in the lagoon. One MGII and one SAR116 OTU (47 and 19) were also separated from the rest, possibly profiting from higher temperatures. More tightly linked with increasing temperatures and APA was the dominant flavobacterial OTU (Sufflavibacter OTU 67) in lagoon samples from days 16 to 21 . Noteably, there was an opposition between the two dominant autotroph OTUs, Synechococcus (9) and Prochlorococcus (4), where the former was closely linked to the increase of PP and Chl at the end of the experiment. Rhodospirillaceae of the Aegean-169 group were positioned opposite to APA, $T$, and PP and close to Prochlorococcus and two chloroplast OTUs (3 and 1677), suggesting they might profit from these autotrophs specifically.

The quadrants resulting from this CCA nicely correspond to the clusters in time found through NMDS (Sect. 3.2.4), with few overlaps between quadrants: the bottom left corresponds to the early phase, the top left to the mid-time phase, and both right quadrants together to the late phase (compare Figs. 6 and 5).

\section{Discussion}

\subsection{Inference of absolute abundances from relative $16 \mathrm{~S}$ data}

Our results rely on the calculation of absolute cell counts from relative $16 \mathrm{~S}$ abundance data obtained by MiSeq sequencing. This is possible by supplementing these data with flow cytometry data and 16S copy numbers per genome. Whereas major trends could likewise be observed in the relative data (Figs. S4, S5), the inferred absolute data give a much more precise picture of the bacterial community and have the power to reveal absolute abundance changes of spe- 


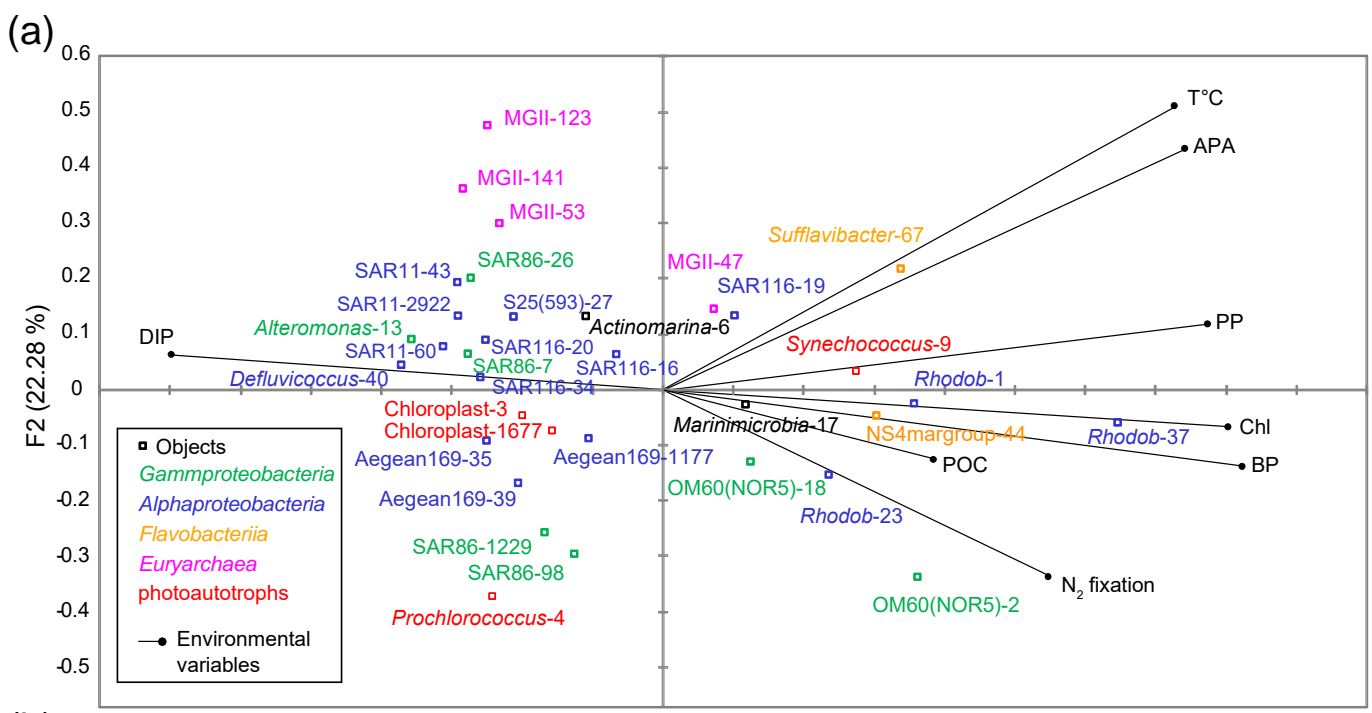

(b)

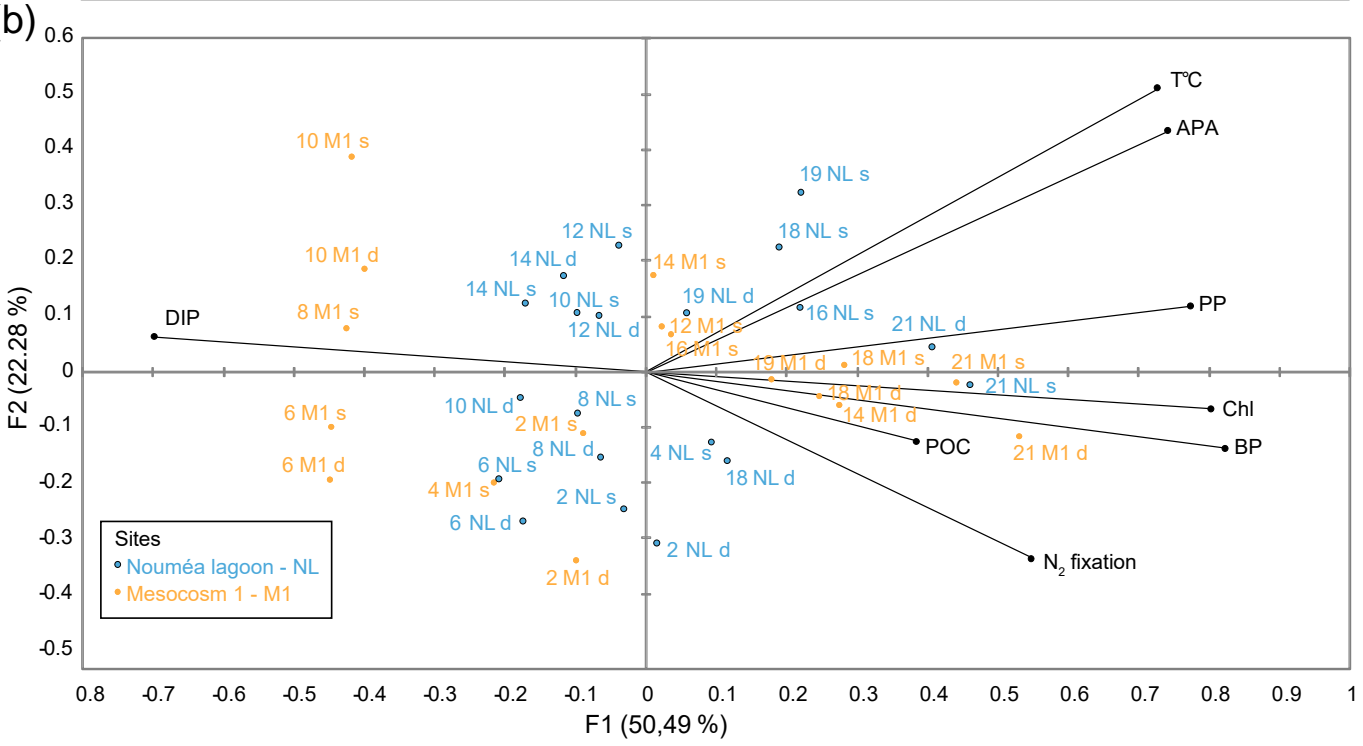

Figure 6. Canonical correspondence analysis (CCA) biplot of bacterial 16S-community structure. Correlations between environmental variables and the first two CCA axes are represented by the lengths and angles of the arrows. The position of OTUs or samples relative to arrows indicates the extent to which the distribution of that OTU or the community composition of that sample is influenced by the environmental parameter represented by that arrow. (a) Ordination of OTUs constrained by the given environmental variables (black lines). Color-coded pen squares mark the 34 most abundant OTUs in the two-dimensional space of the plot. These were one Synechococcus, one Prochlorococcus, and two chloroplast OTUs (photoautotrophs, red); three SAR11, four SAR116, three Aegean169 marine group, three not further classified Rhodobacteraceae (Rhodob), one Rickettsiales S25(593), and one Rhodospirillaceae (Defluviicoccus) OTU (Alphaproteobacteria, blue); four SAR86, two OM60(NOR5) clade (Alteromonadaceae), and one Alteromonas OTU (Gammaproteobacteria, green); one Sufflavibacter and one NS4 marine group OTU (Flavobacteriia, orange); four Marine Group II archaea (MGII, Euryarchaeota, pink); one Candidatus Actinomarina OTU (Acidimicrobiales, black) and one unclassified Marinimicrobia OTU (black). (b) Ordination of sampling sites in the same two-dimensional space. Sites are coded "M1" and "NL" for their origin from mesocosm M1 and the Nouméa lagoon, then " $s$ " or " $d$ " according to the depth sampled (surface $1 \mathrm{~m}$ and deep $12 \mathrm{~m}$, respectively). These codes are prefixed by a number giving day of sampling (from days 2 to 21).

cific groups within. However, there are major potential error sources that need to be mentioned. First of all, the curated table of $16 \mathrm{~S}$ copy numbers per genome is a conscientious estimate and some estimates might well be corrected as more genomes of marine bacteria are being sequenced. Second, flow cytometry might miss some Syn or Pro, if cells are part of aggregates. This would matter if the fraction of Syn or Pro in aggregates changed between samples. To test for biases, we calculated the ratio of Syn to Pro for 16S-copy-numbernormalized $16 \mathrm{~S}$ read counts (16S-norm reads) and for flow 
cytometry counts. In an error-free scenario, both should give the same ratios. With a systematic error source, e.g., constant percentage of Syn in aggregates, the ratios would differ by a similar value in all samples. However, we observed varying ratio differences (Supplement Table S1). In M1, Pro was either underestimated in flow cytometry or Syn underestimated in the 16S data, leading to higher Syn/Pro ratios in flow cytometry data than in $16 \mathrm{~S}$ data for most samples. In the lagoon, this was the case until day 16 , the samples after that showed the opposite. Apart from differential aggregation between samples, a reason for this might be that the assumed $16 \mathrm{~S}$ copy number of two for Syn and one for Pro did not reflect the real populations, but that the initial Syn population had only one copy (or the Pro population two copies), leading to Syn underestimation in $16 \mathrm{~S}$ data. These errors are reduced by using the sum of Syn and Pro for the calculation of the $16 \mathrm{~S}$-norm / cells $\mathrm{mL}^{-1}$ ratio. However, the reader should be aware that the inferred absolute counts are mere estimates.

\subsection{Synechococcus as the most numerous primary producer}

In the world's oceans, the unicellular cyanobacteria Prochlorococcus and Synechococcus constitute the most abundant marine picophytoplankton, amounting together up to $10^{6}$ cells $\mathrm{mL}^{-1}$, and are responsible for up to $50 \%$ of the total $\mathrm{CO}_{2}$ fixation in some regions (Liu et al., 1997; Li, 1994; Veldhuis et al., 1997). Previous studies (Zwirglmaier et al., 2008) showed that Synechococcus abundance is low in the oceanic oligotrophic gyres, reaching only $4 \times 10^{3}$, but is up to $10^{5}$ cells $\mathrm{mL}^{-1}$ in nutrient-rich upwelling regions (see also the data compilation in Flombaum et al. (2013). Therefore, the cell counts reported here for Synechococcus in the New Caledonian lagoon were, with up to $10^{5}$ cells $\mathrm{mL}^{-1}$, among the highest reported thus far for marine waters. In contrast, the maximum values for Prochlorococcus were relatively low. Several studies indicated that Prochlorococcus is adapted to ultra-oligotrophic conditions and is outcompeted by Synechococcus in waters of higher nutrient content, such as upwelling and coastal regions (Partensky et al., 1999a, b), which is consistent with the findings in this study (Leblanc et al., 2016). The Synechococcus group can be further delineated into several major clades with different ecophysiologies (Scanlan et al., 2009). Due to the insufficient phylogenetic resolution, this was not possible based on 16S rRNA gene sequencing. However, in the accompanying metatranscriptome analysis (Pfreundt et al., 2016), we found that the Synechococcus population was dominated by representatives of clade II and to a lower extent, clade IX, within the picophytoplankton subcluster 5.1A. Recent analyses have suggested that the different frequencies of co-occurring Synechococcus ecotypes partition the ocean into four distinct regimes that can be distinguished by temperature, macronutrients, and iron availability, suggesting clade II ecotypes are competitive in warmer, oligotrophic conditions (Sohm et al.,
2015), which is consistent with the results of our metatranscriptomic analysis (Pfreundt et al., 2016). Measurements of BP and PP revealed that the organic matter produced by nondiazotrophic phytoplankton was the major carbon source fueling heterotrophic prokaryotes (Van Wambeke et al., 2015). Our community analysis identified among these primary producers Synechococcus as most numerous contributor.

\subsection{Effects of enclosure and DIP fertilization on the microbial community}

Apart from investigating the effect of changing diazotroph communities on general community structure, we judged to which extent the enclosure and the DIP fertilization in the deployed large mesocosms changed community composition and development compared to the surrounding lagoon waters. Roughly, the $16 \mathrm{~S}$ community partitioned the M1 samples into three periods, an early period of DIP availability (including samples before the spike) until day 8 , a mid-time period of DIP consumption, and a late period of Chl accumulation/P depletion starting with day 18. Remarkably, although we enriched the mesocosms with $\sim 0.8 \mu \mathrm{M}$ DIP and noticed a significant difference between the communities in $\mathrm{M} 1$ and in lagoon waters (Fig. 5a, separation along the second ordination axis, $p<0.001$ ), the evolution of both communities with time was mostly parallel, shown by their parallel separation along the first ordination axis. This indicates an overarching influence of abiotic factors acting on both locations equally, like temperature, which increased during the course of the study. Individual OTUs, like Sufflavibacter, were shown to be positively linked with increasing temperatures. These relations may be linked to significantly enhanced chemotactic abilities at higher temperatures, as was recently shown for a coral pathogen (Garren et al., 2015). Despite the parallel evolution of the full community (rare and abundant OTUs had similar weights in NMDS), community composition and dynamics of single abundant groups in M1 were different to those in the lagoon from the beginning. These differences first became evident with the drop in Synechococcus on days 2 to 4 (Figs. 2a, 3a). In this process, cyanophages might have played a role as suggested by the high gene expression from Myoviridae detected in M1 compared to the lagoon (Pfreundt et al., 2016). Based on the known host association of these T4-like phages (Frank et al., 2013; Ma et al., 2014; Sabehi et al., 2012), these were likely targeting Synechococcus. This event and its putative consequences on the availability of organic material coincided with diatoms sinking out of the water column in the mesocosms, roughly halving in numbers (Leblanc et al., 2016), and overlapped with DIP fertilization on day 4. Thus, it cannot be conclusively determined which had a higher influence on the community differences we observed in the early phase of the experiment, decaying phytoplankton or increased DIP concentrations. Van Wambeke et al. (Van Wambeke et al., 2015) showed that BP was not $\mathrm{P}$ limited on day 4, suggesting that phytoplankton decay had 
the greater effect. Indeed, POC concentrations in M1, but not in the lagoon, increased from $\sim 10$ on day 2 to $15 \mu \mathrm{mol} \mathrm{L}{ }^{-1}$ on day 4 (Berthelot et al., 2015).

We correlated the relative abundances in $\mathrm{M} 1$ and the Nouméa lagoon for all investigated phylogenetic groups (Fig. S2). This approach revealed Alpha- and Gammaproteobacteria as the least correlated classes between M1 and the lagoon. Investigating this aspect at higher taxonomic resolution showed that SAR11 and SAR86 temporal dynamics differed the most, suggesting that these groups were the most sensitive to changing nutrient sources. SAR11 was present at comparatively low numbers compared to other reports (Morris et al., 2002). We used filters with $0.45 \mu \mathrm{m}$ pore size, so it cannot be excluded that SAR11 (average size $0.2 \mu \mathrm{m} \times 0.4 \mu \mathrm{m})$ and the even smaller Candidatus Actinomarina were lost at the beginning of filtering and retained when more other cells were already on the filter. Thus, we have possibly missed a substantial fraction of these groups in this study. Nevertheless, we can expect the loss rate to be very similar across all samples, due to the following reasons: $16 \mathrm{~S}$ and metatranscriptomics analyses were done from DNA and RNA isolated together from the same filter. Transcript abundances were tightly correlated (Pearson correlation 0.88 in M1, and 0.96 in the lagoon) between SAR86 and SAR11 (Pfreundt et al., 2016) across all samples. With different loss rates of SAR11 in different samples this correlation should not be possible. SAR86, like SAR11, shows metabolic streamlining, but while SAR11 genomes contain putative genes for synthesis of most amino acids (Grote et al., 2012), a substantial fraction of SAR86 is probably auxotroph for Met, His, and Arg (Dupont et al., 2012). Oppositely, SAR86 genomes encode a disproportionally high number of TonB-dependent outer membrane receptors (TBDRs) that allow transport of $>600$ Da molecules, including carbohydrates and lipids, combined with lipase genes and an expanded sugar utilization metabolism, whereas SAR11 genomes are not known to contain any TBDR genes and have strongly reduced sugar utilization capabilities (Dupont et al., 2012). In our accompanying metatranscriptome study, transcripts for TBDRs and phospholipase (days 14-16) from SAR86 were highly abundant, suggesting that membrane lipids were used as an energy source (Pfreundt et al., 2016). Cultivation experiments of SAR11 representatives have shown their ability to utilize a wide variety of small organic molecules, including peptides, to generate energy (Tripp, 2013). The SAR11 subgroup Ia (surface 1) representative Pelagibacter ubique was able to substitute one of its glycine by glycolate (Carini et al., 2013), which is one of the main excretion byproducts of phytoplankton and is assumed to be abundant in phytoplankton release. Finally, both SAR11 and SAR86 genomes contain proteorhodopsin genes, potentially providing an additional energy source, but the corresponding transcript levels were much higher in SAR11 than in SAR86 during the VAHINE experiment (Pfreundt et al., 2016).
Strikingly, for both SAR11 and SAR86, 16S abundance was decoupled from the respective total transcript accumulation presented in the companion paper, whereas the transcript abundances of both clades were highly correlated (Pfreundt et al., 2016), and specific abundant SAR11 and SAR86 OTUs shared a similar environmental niche (Fig. 6). Dupont et al. (Dupont et al., 2012) hypothesized that, due to their different resource specializations, SAR11 and SAR86 compete only slightly for dissolved organic carbon (DOC), which would allow for their co-existence, albeit without explaining their tight transcriptional correlation. Dominant SAR86 OTUs exhibited niche partitioning in the constrained ordination (Fig. 6). The temporal variation of two OTUs was close to SAR11 and Alteromonas and of another two OTUs close to Prochlorococcus, suggesting different sources of DOC were utilized by these SAR86 subtypes. On $16 \mathrm{~S}$ sequence level, pairwise alignments of these four SAR86 OTUs showed sequence identities between 86.3\% (OTUs 26 and 1229) and $94.9 \%$ (OTUs 7 and 98). Thus, those SAR86 OTUs sharing a niche were not more similar on $16 \mathrm{~S}$ level than in between niches.

An aspect of special interest was to recognize community changes which could be attributed to the DIP fertilization in M1. CCA suggested that the taxon profiting most from DIP fertilization was Defluviicoccus (Rhodospirillaceae). Apart from the maximum on day 6 in M1, this genus had similar abundances also in the Nouméa lagoon (Supplement). Defluviicoccus-related bacteria were initially described from enhanced biological phosphorus removal systems (Maszenan et al., 2005; McIlroy and Seviour, 2009; Mielczarek et al., 2013). In such systems, used to treat wastewater, Defluviicoccus are known as glycogen-accumulating bacteria, competing with polyphosphate-accumulating organisms (Burow et al., 2007; McIlroy and Seviour, 2009; Wong et al., 2004; Wong and Liu, 2007). There are only few studies reporting Defluviicoccus-related bacteria in marine samples, and, if so, these were associated with marine invertebrates (Enomoto et al., 2012; Fan et al., 2013). Our data show a minor population of Defluviicoccus-related bacteria in the Nouméa lagoon that could benefit from the addition of fresh phosphorus in M1. Note, however, that the dominant OTU in this genus was only $83 \%$ identical to Defluviicoccus vanus $16 \mathrm{~S}$ but $99 \%$ identical to environmental sequences that, according to SILVA taxonomy for SSU release 119 and 123, are leaves of the same node as $D$. vanus and were thus classified as Defluviicoccus (name of the node). Phylogenetic placement of the here described Defluviicoccus OTUs showed their association with marine environmental Defluviicoccus 16S (Fig. S3).

\subsection{Effects of DIP depletion at the end of the experiment}

Some aspects of the taxonomic succession after day 13 , when DIP was mainly depleted, can be related to the strategies used for adaptation to $\mathrm{P}$ limitation. Among autotrophs, the 
main trend observed in M1 and the lagoon waters was the opposition of Prochlorococcus and Synechococcus with Synechococcus reaching higher abundances in M1 at the end of the experiment compared to the beginning, when DIP was comparatively low. Both expressed AP mainly 2 days after their respective 16S abundance peak (Pfreundt et al., 2016), suggesting that the increase in cell numbers led to a higher phosphorous demand that was subsequently adapted to. Incorporation of sulfolipids instead of phospholipids into membrane lipids is an ecological strategy developed by cyanobacteria for an advantage in P deficient environments (Van Mooy et al., 2006, 2009). The ability to synthesize Sulfoquinovosyl diacylglycerols in place of phosphatidylglycerol in P-limited cultures can save 5 to $43 \%$ of total cellular phosphorus demand and is highly variable according to the strain tested (Van Mooy et al., 2009). SqdB, a gene encoding a sulfolipid synthesis protein, was mainly transcribed by Synechococcus and less by Prochlorococcus (Pfreundt et al., 2016) and transcript abundance changes corresponded to changes in $16 \mathrm{~S}$ abundance. In the North Atlantic Ocean, Synechococcus are also good competitors with Prochlorococcus for DIP and ATP uptake (Michelou et al., 2011). A variety of heterotrophs expressed AP mainly after day 10, possibly to the benefit of other populations. Indeed, metagenomic analyses showed that $59 \%$ of marine bacterial APs are extracellular, periplasmic, or located at the outer membrane (Luo et al., 2009). Possibly, DIP release through extracellular APA may have provided $\mathrm{P}$ to neighboring cells that cannot synthesize this enzyme, and such effects could possibly be emphasized in macro-aggregate gels seen during P2 in the VAHINE experiment (Berman-Frank et al., 2016).

\subsection{Possible functional roles of bacterial subcommunities in the degradation of organic matter}

The concerted increase of Cytophaga and Flavobacteriia towards the end of the experiment is a recurrent feature seen in older studies based on plateable strains (Fukami et al., 1981b; Painting et al., 1989) and in molecular studies allowing access to the uncultivable community (Teeling et al., 2012). Both Cytophaga and Flavobacteriia profit from phytoplankton blooms and have often been found in marine snow (DeLong et al., 1993; Fontanez et al., 2015; Teeling et al., 2012). Members of the Flavobacteriia are known to degrade organic matter, some even specializing on algal-derived organic matter (Bauer et al., 2006; Bowman, 2006). In the lagoon, members of the Flavobacteriaceae reached even higher abundances than in M1, arguing against M1-specific effects being the reason for their increase. The occurrence of different Flavobacteriaceae phylotypes seems to depend on the nature of the dominant phytoplankton species (Pinhassi et al., 2004). Information retrieved from analysis of cultured representatives showed a high capacity to degrade high molecular weight molecules, which is in line with the high ectoenzy- matic activities generally associated with the end of blooms (Chróst, 1992; Riemann et al., 2000). The quality of organic matter issued from specific phytoplankton detritus influences bacterial community succession, and while the potential for polymer degradation appears to be widespread among different phyla it is restricted to some specialized species (Landa et al., 2014; Murray et al., 2007). Our data indicate that both in M1 and the lagoon, available organic components favored growth of diverse flavobacteria, probably enhanced by increasing temperatures during $\mathrm{P} 2$.

Our data further indicate that Rhodobacteraceae, when abundant, assimilate much more organic matter than other heterotrophs seen in this study, as dynamics in BP were closely linked to this group. This was not only shown by CCA (Fig. 6) but is also evident from directly comparing BP (Fig. 1e) to Rhodobacteraceae abundance. Both striking BP peaks on day 4 and day 21 in M1 correspond to concomitant Rhodobacteraceae abundance peaks, while no other heterotrophic groups showed these peaks. Rhodobacteraceae are considered ecological generalists, with large gene inventories, but they cannot be easily condensed in an ecologically differentiated cluster (Newton et al., 2010). Roseobacter, a common marine member of the Rhodobacteraceae, have a variety of metabolic pathways that confer advantages among other bacteria and facilitate interaction with, and attachment to, phytoplankton detritus. They can produce quorum sensing molecules, vitamins, and antimicrobial compounds (Buchan et al., 2014). CCA showed two dominating Rhodobacteraceae OTUs linked with Chl concentrations (Fig. 5), which argues for their ability to access phytoplankton detritus, while one OTU was closely linked with $\mathrm{N}_{2}$ fixation. Notably, none of these three OTUs represented the Thalassobius sp. OTU that was responsible for the Rhodobacteraceae peak on day 4 .

\subsection{The diazotroph community and its impact on the heterotroph-community structure}

Diazotroph-community structure (Figs. 3f, 4f) probably changed in M1 due to DIP fertilization and reduced turbulence, with Cyanothece-like cells profiting and forming large aggregates during P2 (Bonnet et al., 2015b). Our 16S-based diazotroph abundances compare reasonably well with those found by quantitative PCR of the nifH gene (Turk-Kubo et al., 2015), if we assume that those $16 \mathrm{~S}$ reads classified as Calothrix are indeed mostly Richelia (Het-1). The SILVA database positions Richelia below the Calothrix node, and the metatranscriptome data published in this issue show a substantial Richelia read fraction and only little Calothrix (Pfreundt et al., 2016), supporting this assumption. Further, UCYN-C (Cyanothece) nifH gene abundance was at maximum 100 copies $\mathrm{mL}^{-1}$ in M1 (Turk-Kubo et al., 2015), which matches well the maximal 400 cells $\mathrm{mL}^{-1}$ that we inferred from relative $16 \mathrm{~S}$ values for Cyanothece (Fig. 3f). Note that there are also non-diazotrophic Cyanothece repre- 
sentatives, and thus the second number can be expected to be larger. This is remarkable given the different methods used to produce these numbers.

The higher Trichodesmium abundance inside M1 after its deployment might be attributed to entrapment of filaments that were not present in the lagoon anymore when the sampling started, likely due to high tide currents. The reduction in the number of $16 \mathrm{~S}$ tags belonging to Trichodesmium following the DIP fertilization on the evening of day 4 was unexpected. To the contrary, the combined effects of reduced turbulence and $\mathrm{P}$ limitation was thought to trigger a Trichodesmium bloom. However, a Trichodesmium bloom was observed at the end of the VAHINE experiment in the lagoon (Spungin et al., 2016), demonstrating that either the small numbers of existing filaments were competent to build up a bloom rapidly or that most Trichodesmium resided in deeper waters before the bloom. While we did see cyanophage gene expression in $\mathrm{M} 1$ in the accompanying metatranscriptome study (Pfreundt et al., 2016), the known host ranges of those phages suggest that they rather would act on Synechococcus, excluding viral lysis as the reason for the Trichodesmium decline. Thus, there were likely other factors involved that deserve further investigation. Trichodesmium has comparatively low growth rates (Turk-Kubo et al., 2015), so enhanced competition after DIP fertilization might be such a factor.

Average $\mathrm{N}_{2}$-fixation rates of $27.3 \pm 1.0 \mathrm{nmol} \mathrm{NL}^{-1} \mathrm{~d}^{-1}$ were measured inside the mesocosms during P2 (days 1523), and with $69.7 \mathrm{nmol} \mathrm{N} \mathrm{L}^{-1} \mathrm{~d}^{-1}$ very high maximum rates were reached in $\mathrm{M} 1$ between days 18 and 21. A shortterm experiment performed by Bonnet et al. (Bonnet et al., 2015b) indicated that DDN was efficiently transferred to non-diazotrophic microbial communities during P2: after $24 \mathrm{~h}, 16 \pm 6 \%$ of the fixed $\mathrm{N} 2$ was released in the dissolved nitrogen pool and $18 \pm 4 \%$ was transferred to nondiazotrophic picoplankton. We show that almost all heterotrophic classes analyzed here ( $>0.5 \%$ relative abundance) increased during this period (Fig. 3). Another publication in this issue showed that BP was stimulated after shortterm ammonium plus nitrate enrichments on days 4 and 20 (Van Wambeke et al., 2015). This speaks for a positive effect of released DDN on heterotrophic growth during P2, but effects through phytoplankton growth and decay probably also played a role. Indeed, nitrogen inputs from $\mathrm{N}_{2}$ fixation alone were not sufficient to sustain BP (Van Wambeke et al., 2015). Constrained ordination showed that generally, temporal variation of dominant Rhodobacteraceae, Halieaceae (OM60(NOR5), in SILVA release 119 within the Alteromonadaceae), and Flavobacteriia could be partially be explained with changes in $\mathrm{N}_{2}$ fixation, whereas variation in other alphaproteobacteria (mainly SAR11, SAR116, and Rhodospirillaceae), SAR86, Euryarchaeota, and Alteromonas abundances were not explainable by $\mathrm{N}_{2}$ fixation (Fig. 6), indicating the involvement of additional factors. However, it appears very clear that the shift within the diazotroph community from the dominant diazotrophs Richelia and Trichodesmium to UCYN-C after day 14 , together with very high $\mathrm{N}_{2}$-fixation rates (Bonnet et al., 2015b), led to an increase in abundance of almost all heterotrophic groups investigated here, consistent with N limitation of BP (Van Wambeke et al., 2015).

\section{Conclusions}

We show that despite their large size $\left(>50 \mathrm{~m}^{3}\right)$, the VAHINE mesocosms led to significant changes in the microbial community structure, probably initiated by decay of Synechococcus and diatoms (Leblanc et al., 2016), albeit not exhibiting a typical bottle effect with a copiotroph-dominated community. The accompanying metatranscriptome study for M1 showed gene expression from cyanophages, which might have contributed to Synechococcus decay. Fertilization with $0.8 \mu \mathrm{M}$ DIP on day 4 did not have directly observable effects on the overall community, as samples from before and 4 days after fertilization clustered together, but likely influenced development of individual populations, like Defluviicoccusrelated bacteria or UCYN-C (Cyanothece) diazotrophs. The latter increased after day 10 only in the mesocosms and were probably limited by temperature before that (Turk-Kubo et al., 2015). The shift of the dominant diazotroph from Richelia and Trichodesmium to UCYN-C after day 14 (Turk-Kubo et al., 2015), together with extremely high $\mathrm{N}_{2}$-fixation rates (Bonnet et al., 2015b), led to an increase in abundance of almost all heterotrophic groups investigated here, consistent with N-limited BP (Van Wambeke et al., 2015).

Linked with the observation of tight correlation between SAR11 and SAR86 transcription during a diel cycle (Aylward et al., 2015) and over 3 weeks (Pfreundt et al., 2016), we show that the temporal dynamics of individual OTUs of these clades over 3 weeks can be explained by very similar combinations of environmental variables. With the results of this work we present for the first time in this ecosystem an in-depth analysis of the prokaryotic diversity and community structure and of their changes over time with a focus on diazotrophic organisms. We correlate the prokaryotic community structure with effects of DIP fertilization, of enclosure vs. open lagoon waters, and with the fate of DDN and DOC. The determined microbial diversity was very high, and we provide evidence for previously unknown niche partitioning, e.g., among dominant SAR86 OTUs. These results suggest a plethora of still unknown metabolic and regulatory interactions to occur within these marine microbial communities that are worth being explored further.

\section{Data availability}

All raw sequencing data can be downloaded from NCBI's BioProject database under the accession number BioProject PRJNA304389 (Pfreundt et al., 2015). 


\section{The Supplement related to this article is available online at doi:10.5194/bg-13-2319-2016-supplement.}

Author contributions. Sophie Bonnet is the chief scientist responsible for the VAHINE program; she designed and executed the mesocosm experiment and measured $\mathrm{N}_{2}$ fixation. France Van Wambeke sampled for and prepared Figs. 1 and 6, Mathieu Caffin performed flow cytometry, Wolfgang R. Hess and Ulrike Pfreundt took samples for DNA extraction, Ulrike Pfreundt prepared and analyzed 16S rRNA gene amplicons and prepared all other figures, U1rike Pfreundt, France Van Wambeke, and Wolfgang R. Hess drafted the manuscript, and all authors reviewed the manuscript.

Acknowledgements. Funding for this research was provided by the Agence Nationale de la Recherche (ANR starting grant VAHINE ANR-13-JS06-0002), INSU-LEFE-CYBER program, GOPS, IRD, and MIO. The participation of UP and WRH was supported by the German-Israeli Research Foundation (GIF), project number 1133-13.8/2011, and the MiSeq-based microbial community analysis by the EU project MaCuMBA (Marine Microorganisms: Cultivation Methods for Improving their Biotechnological Applications; grant agreement no. 311975) to Wolfgang R. Hess. The authors thank the captain and crew of the R/V Alis. We acknowledge the SEOH divers' service from the IRD research center of Nouméa (E. Folcher, B. Bourgeois, and A. Renaud) and from the Observatoire Océanologique de Villefranche-sur-Mer (OOV, J. M. Grisoni) as well as the technical service of the IRD research center of Nouméa for their helpful technical support. C. Guieu, F. Louis, and J. M. Grisoni (Laboratoire d'Océanographie de Villefranche and Observatoire céalonologique de Villefranchesur-Mer) are warmly thanked for the mesocosms design and their useful advice for deployment. The authors thank Anne Desnues and Dina Spungin for help in sampling, T. Moutin, M. Rodier, and $\mathrm{H}$. Berthelot for providing their data, Danny Ionescu (Leibniz Institute for Freshwater Ecology and Inland Fisheries, Berlin) for introduction to and initial help with the SILVA pipeline, and Craig Nelson (University of Hawai'i at Manoa) for advice on NMDS analysis. We are grateful to the Regional Flow Cytometry Platform for Microbiology (PRECYM) of the Mediterranean Institute of Oceanography for the flow cytometry analyses. We thank the reviewers of this manuscript for their valuable comments.

Edited by: E. Marañón

\section{References}

Alonso-Sáez, L. and Gasol, J. M.: Seasonal variations in the contributions of different bacterial groups to the uptake of lowmolecular-weight compounds in northwestern Mediterranean coastal waters, Appl. Environ. Microbiol., 73, 3528-3535, doi:10.1128/AEM.02627-06, 2007.

Aylward, F. O., Eppley, J. M., Smith, J. M., Chavez, F. P., Scholin, C. A., and DeLong, E. F.: Microbial community transcriptional networks are conserved in three domains at ocean basin scales, P. Natl. Acad. Sci. USA, 112, 5443-5448, doi:10.1073/pnas.1502883112, 2015.

Bauer, M., Kube, M., Teeling, H., Richter, M., Lombardot, T., Allers, E., Würdemann, C. A., Quast, C., Kuhl, H., Knaust, F., Woebken, D., Bischof, K., Mussmann, M., Choudhuri, J. V., Meyer, F., Reinhardt, R., Amann, R. I., and Glöckner, F. O.: Whole genome analysis of the marine Bacteroidetes "Gramella forsetii" reveals adaptations to degradation of polymeric organic matter, Environ. Microbiol., 8, 2201-2213, doi:10.1111/j.14622920.2006.01152.x, 2006.

Beier, P. and de Albuquerque, F. S.: Environmental diversity as a surrogate for species representation, Conserv. Biol., 29, 14011410, doi:10.1111/cobi.12495, 2015.

Berman-Frank, I., Spungin, D., Rahav, E., Van Wambeke, F., TurkKubo, K., and Moutin, T.: Dynamics of transparent exopolymer particles (TEP) during the VAHINE mesocosm experiment in the New Caledonia lagoon, Biogeosciences Discuss., doi:10.5194/bg-2015-612, in review, 2016.

Berthelot, H., Moutin, T., L'Helguen, S., Leblanc, K., Hélias, S., Grosso, O., Leblond, N., Charrière, B., and Bonnet, S.: Dinitrogen fixation and dissolved organic nitrogen fueled primary production and particulate export during the VAHINE mesocosm experiment (New Caledonia lagoon), Biogeosciences, 12, 40994112, doi:10.5194/bg-12-4099-2015, 2015.

Biddanda, B. and Pomeroy, L.: Microbial aggregation and degradation of phytoplankton-derived detritus in seawater. I. Microbial succession, Mar. Ecol.-Prog. Ser., 42, 79-88, doi:10.3354/meps042079, 1988.

Biegala, I. C. and Raimbault, P.: High abundance of diazotrophic picocyanobacteria $(<3 \mu \mathrm{m})$ in a Southwest Pacific coral lagoon, Aquat. Microb. Ecol., 51, 45-53, doi:10.3354/ame01185, 2008.

Bonnet, S., Rodier, M., Turk-Kubo, K. A., Germineaud, C., Menkes, C., Ganachaud, A., Cravatte, S., Raimbault, P., Campbell, E., Quéroué, F., Sarthou, G., Desnues, A., Maes, C., and Eldin, G.: Contrasted geographical distribution of N2 fixation rates and nifH phylotypes in the Coral and Solomon Seas (South-Western Pacific) during austral winter conditions, Global Biogeochem. Cy., 29, 1874-1892, doi:10.1002/2015GB005117, 2015a.

Bonnet, S., Berthelot, H., Turk-Kubo, K., Fawcett, S., Rahav, E., l'Helguen, S., and Berman-Frank, I.: Dynamics of $\mathrm{N}_{2}$ fixation and fate of diazotroph-derived nitrogen in a low nutrient low chlorophyll ecosystem: results from the VAHINE mesocosm experiment (New Caledonia), Biogeosciences Discuss., 12, 1957919626, doi:10.5194/bgd-12-19579-2015, 2015 b.

Bonnet, S., Moutin, T., Rodier, M., Grisoni, J. M., Louis, F., Folcher, E., Bourgeois, B., Boré, J. M., and Renaud, A.: Introduction to the project VAHINE: VAriability of vertical and tropHIc transfer of diazotroph derived $\mathrm{N}$ in the south wEst Pacific, Biogeosciences Discuss., doi:10.5194/bg-2015-615, in review, 2016.

Bowman, J. P.: The Marine Clade of the Family Flavobacteriaceae: The Genera Aequorivita, Arenibacter, Cellulophaga, Croceibacter, Formosa, Gelidibacter, Gillisia, Maribacter, Mesonia, Muricauda, Polaribacter, Psychroflexus, Psychroserpens, Robiginitalea, Salegentibacter, Tenacibaculum, Ulvibacter, Vitellibacter and Zobellia, in The Prokaryotes, Springer New York, 677-694, doi:10.1007/0-387-30747-8_26, 2006. 
Braak, C. J. F.: Canonical Correspondence Analysis: A new eigenvector technique for multivariate direct gradient analysis, Ecology, 67, 1167-1179, doi:10.2307/1938672, 1986.

Buchan, A., LeCleir, G. R., Gulvik, C. A., and González, J. M.: Master recyclers: features and functions of bacteria associated with phytoplankton blooms, Nat. Rev. Microbiol., 12, 686-698, doi:10.1038/nrmicro3326, 2014.

Burow, L. C., Kong, Y., Nielsen, J. L., Blackall, L. L., and Nielsen, P. H.: Abundance and ecophysiology of Defluviicoccus spp., glycogen-accumulating organisms in full-scale wastewater treatment processes, Microbiology, 153, 178-185, doi:10.1099/mic.0.2006/001032-0, 2007.

Carini, P., Steindler, L., Beszteri, S., and Giovannoni, S. J.: Nutrient requirements for growth of the extreme oligotroph "Candidatus Pelagibacter ubique" HTCC1062 on a defined medium, ISME J., 7, 592-602, doi:10.1038/ismej.2012.122, 2013.

Chróst, R. J.: Significance of bacterial ectoenzymes in aquatic environments, Hydrobiologia, 243/244, 61-70, 1992.

DeLong, E. F., Franks, D. G., and Alldredge, A. L.: Phylogenetic diversity of aggregate-attached vs. free-living marine bacterial assemblages, Limnol. Oceanogr., 38, 924-934, doi:10.4319/lo.1993.38.5.0924, 1993.

Dupont, C. L., Rusch, D. B., Yooseph, S., Lombardo, M.-J., Alexander Richter, R., Valas, R., Novotny, M., Yee-Greenbaum, J., Selengut, J. D., Haft, D. H., Halpern, A. L., Lasken, R. S., Nealson, K., Friedman, R., and Craig Venter, J.: Genomic insights to SAR86, an abundant and uncultivated marine bacterial lineage, ISME J., 6, 1186-1199, doi:10.1038/ismej.2011.189, 2012.

Edgar, R. C.: UPARSE: highly accurate OTU sequences from microbial amplicon reads, Nat. Methods, 10, 996-998, doi:10.1038/nmeth.2604, 2013.

Enomoto, M., Nakagawa, S., and Sawabe, T.: Microbial communities associated with holothurians: presence of unique bacteria in the coelomic fluid, Microbes Environ., 27, 300-305, 2012.

Fan, L., Liu, M., Simister, R., Webster, N. S., and Thomas, T.: Marine microbial symbiosis heats up: the phylogenetic and functional response of a sponge holobiont to thermal stress, ISME J., 7, 991-1002, doi:10.1038/ismej.2012.165, 2013.

Flombaum, P., Gallegos, J. L., Gordillo, R. A., Rincón, J., Zabala, L. L., Jiao, N., Karl, D. M., Li, W. K. W., Lomas, M. W., Veneziano, D., Vera, C. S., Vrugt, J. A., and Martiny, A. C.: Present and future global distributions of the marine Cyanobacteria Prochlorococcus and Synechococcus, P. Natl. Acad. Sci. USA, 110, 9824 9829, doi:10.1073/pnas.1307701110, 2013.

Fontanez, K. M., Eppley, J. M., Samo, T. J., Karl, D. M., and DeLong, E. F.: Microbial community structure and function on sinking particles in the North Pacific Subtropical Gyre, Front. Microbiol., 6, , doi:10.3389/fmicb.2015.00469, 2015.

Frank, J. A., Lorimer, D., Youle, M., Witte, P., Craig, T., Abendroth, J., Rohwer, F., Edwards, R. A., Segall, A. M., and Burgin, A. B.: Structure and function of a cyanophage-encoded peptide deformylase, ISME J., 7, 1150-1160, doi:10.1038/ismej.2013.4, 2013.

Fukami, K., Simidu, U., and Taga, N.: A microbiological study on the decline process of a phyto plankton bloom in Aburatsubo Inlet, Kanagawa, Japan, Bull. Plankton. Soc. Jpn., 28, 33-41, 1981a.

Fukami, K., Simidu, U., and Taga, N.: Fluctuation of the communities of heterotrophic bacteria during the decomposition pro- cess of phytoplankton, J. Exp. Mar. Biol. Ecol., 55, 171-184, doi:10.1016/0022-0981(81)90110-6, 1981b.

Garcia, N., Raimbault, P., and Sandroni, V.: Seasonal nitrogen fixation and primary production in the Southwest Pacific: nanoplankton diazotrophy and transfer of nitrogen to picoplankton organisms, Mar. Ecol.-Prog. Ser., 343, 25-33, doi:10.3354/meps06882, 2007.

Garren, M., Son, K., Tout, J., Seymour, J. R., and Stocker, R.: Temperature-induced behavioral switches in a bacterial coral pathogen, ISME J., online first, doi:10.1038/ismej.2015.216, 2015.

Grote, J., Thrash, J. C., Huggett, M. J., Landry, Z. C., Carini, P., Giovannoni, S. J., and Rappé, M. S.: Streamlining and core genome conservation among highly divergent members of the SAR11 clade, mBio, 3, e00252-12, doi:10.1128/mBio.00252-12, 2012.

Klindworth, A., Pruesse, E., Schweer, T., Peplies, J., Quast, C., Horn, M., and Glöckner, F. O.: Evaluation of general 16S ribosomal RNA gene PCR primers for classical and next-generation sequencing-based diversity studies, Nucleic Acids Res., 41, e1, doi:10.1093/nar/gks808, 2013.

Landa, M., Cottrell, M. T., Kirchman, D. L., Kaiser, K., Medeiros, P. M., Tremblay, L., Batailler, N., Caparros, J., Catala, P., Escoubeyrou, K., Oriol, L., Blain, S., and Obernosterer, I.: Phylogenetic and structural response of heterotrophic bacteria to dissolved organic matter of different chemical composition in a continuous culture study, Environ. Microbiol., 16, 1668-1681, doi:10.1111/1462-2920.12242, 2014.

Lebaron, P., Servais, P., Troussellier, M., Courties, C., Muyzer, G., Bernard, L., Schäfer, H., Pukall, R., Stackebrandt, E., Guindulain, T., and Vives-Rego, J.: Microbial community dynamics in Mediterranean nutrient-enriched seawater mesocosms: changes in abundances, activity and composition, FEMS Microbiol. Ecol., 34, 255-266, 2001.

Leblanc, K., Cornet, V., Caffin, M., Rodier, M., Desnues, A., Berthelot, H., Turk-Kubo, K., and Heliou, J.: Phytoplankton community structure in the VAHINE MESOCOSM experiment, Biogeosciences Discuss., doi:10.5194/bg-2015-605, in review, 2016.

Liu, H., Nolla, H. A., and Campbell, L.: Prochlorococcus growth rate and contribution to primary production in the equatorial and subtropical North Pacific Ocean, Aquat. Microb. Ecol., 12, 3947, doi:10.3354/ame012039, 1997.

Li, W. K. W.: Primary production of prochlorophytes, cyanobacteria, and eucaryotic ultraphytoplankton: measurements from flow cytometric sorting, Limnol. Oceanogr., 39, 169-175, 1994.

Luo, H., Benner, R., Long, R. A., and Hu, J.: Subcellular localization of marine bacterial alkaline phosphatases, P. Natl. Acad. Sci USA, 106, 21219-21223, doi:10.1073/pnas.0907586106, 2009.

Luo, Y.-W., Doney, S. C., Anderson, L. A., Benavides, M., BermanFrank, I., Bode, A., Bonnet, S., Boström, K. H., Böttjer, D., Capone, D. G., Carpenter, E. J., Chen, Y. L., Church, M. J., Dore, J. E., Falcón, L. I., Fernández, A., Foster, R. A., Furuya, K., Gómez, F., Gundersen, K., Hynes, A. M., Karl, D. M., Kitajima, S., Langlois, R. J., LaRoche, J., Letelier, R. M., Marañón, E., McGillicuddy Jr., D. J., Moisander, P. H., Moore, C. M., Mouriño-Carballido, B., Mulholland, M. R., Needoba, J. A., Orcutt, K. M., Poulton, A. J., Rahav, E., Raimbault, P., Rees, A. P., Riemann, L., Shiozaki, T., Subramaniam, A., Tyrrell, T., TurkKubo, K. A., Varela, M., Villareal, T. A., Webb, E. A., White, A. E., Wu, J., and Zehr, J. P.: Database of diazotrophs in global 
ocean: abundance, biomass and nitrogen fixation rates, Earth Syst. Sci. Data, 4, 47-73, doi:10.5194/essd-4-47-2012, 2012.

Maszenan, A. M., Seviour, R. J., Patel, B. K. C., Janssen, P. H., and Wanner, J.: Defluvicoccus vanus gen. nov., sp. nov., a novel Gram-negative coccus/coccobacillus in the "Alphaproteobacteria" from activated sludge, Int. J. Syst. Evol. Micr., 55, 21052111, doi:10.1099/ijs.0.02332-0, 2005.

Ma, Y., Allen, L. Z., and Palenik, B.: Diversity and genome dynamics of marine cyanophages using metagenomic analyses, Environ. Microbiol., 6, 583-594, 2014.

McIlroy, S. and Seviour, R. J.: Elucidating further phylogenetic diversity among the Defluviicoccus-related glycogenaccumulating organisms in activated sludge, Environ. Microbiol., 1, 563-568, doi:10.1111/j.1758-2229.2009.00082.x, 2009.

Michelou, V. K., Lomas, M. W., and Kirchman, D. L.: Phosphate and adenosine-5' -triphosphate uptake by cyanobacteria and heterotrophic bacteria in the Sargasso Sea, Limnol. Oceanogr., 56, 323-332, doi:10.4319/lo.2011.56.1.0323, 2011.

Mielczarek, A. T., Nguyen, H. T. T., Nielsen, J. L., and Nielsen, P. H.: Population dynamics of bacteria involved in enhanced biological phosphorus removal in Danish wastewater treatment plants, Water Res., 47, 1529-1544, doi:10.1016/j.watres.2012.12.003, 2013.

Moisander, P. H., Beinart, R. A., Hewson, I., White, A. E., Johnson, K. S., Carlson, C. A., Montoya, J. P., and Zehr, J. P.: Unicellular cyanobacterial distributions broaden the oceanic $\mathrm{N}_{2}$ fixation domain, Science, 327, 1512-1514, doi:10.1126/science.1185468, 2010.

Morris, R. M., Rappé, M. S., Connon, S. A., Vergin, K. L., Siebold, W. A., Carlson, C. A., and Giovannoni, S. J.: SAR11 clade dominates ocean surface bacterioplankton communities, Nature, 420, 806-810, doi:10.1038/nature01240, 2002.

Moutin, T., Karl, D. M., Duhamel, S., Rimmelin, P., Raimbault, P., Van Mooy, B. A. S., and Claustre, H.: Phosphate availability and the ultimate control of new nitrogen input by nitrogen fixation in the tropical Pacific Ocean, Biogeosciences, 5, 95-109, doi:10.5194/bg-5-95-2008, 2008.

Murray, A. E., Arnosti, C., Rocha, C. L. D. L., Grossart, H., and Passow, U.: Microbial dynamics in autotrophic and heterotrophic seawater mesocosms, II. Bacterioplankton community structure and hydrolytic enzyme activities, Aquat. Microb. Ecol., 49, 123141, doi:10.3354/ame01139, 2007.

Nagata, T.: Production mechanisms of dissolved organic matter, in Microbial Ecology of the Oceans, edited by: Kirchman, D. L., 121-152, Wiley, Lissabon., 2000.

Newton, R. J., Griffin, L. E., Bowles, K. M., Meile, C., Gifford, S., Givens, C. E., Howard, E. C., King, E., Oakley, C. A., Reisch, C. R., Rinta-Kanto, J. M., Sharma, S., Sun, S., Varaljay, V., VilaCosta, M., Westrich, J. R., and Moran, M. A.: Genome characteristics of a generalist marine bacterial lineage, ISME J., 4, 784798, doi:10.1038/ismej.2009.150, 2010.

Oksanen, J., Blanchet, F. G., Kindt, R., Legendre, P., Minchin, P. R., O'Hara, R. B., Simpson, G. L., Solymos, P., Stevens, M. H. H., and Wagner, H.: vegan: Community Ecology Package, available at: http://CRAN.R-project.org/package=vegan (last access: 15 February 2016), 2015.

Painting, S. J., Lucas, M. I., and Muir, D. G.: Fluctuations in heterotrophic bacterial community structure, activity and production in response to development and decay of phytoplankton in a microcosm, Mar. Ecol.-Prog. Ser., 53, 129-141, 1989.

Partensky, F., Blanchot, J., and Vaulot, D.: Differential distribution and ecology of Prochlorococcus and Synechococcus in oceanic waters?: a review, Bull. Inst. Océan., 19, 457-475, 1999a.

Partensky, F., Hess, W. R., and Vaulot, D.: Prochlorococcus, a marine photosynthetic prokaryote of global significance, Microbiol. Mol. Biol. R., 63, 106-127, 1999b.

Pfreundt, U., Spungin, D., Berman-Frank, I., Bonnet, S., and Hess, W. R.: 16S rRNA gene amplicon and metatranscriptomic datasets from the VAHINE mesocosm experiment in the New Caledonian Lagoon, South West Pacific, http://www.ncbi.nlm.nih.gov/ bioproject/PRJNA304389/, 2015.

Pfreundt, U., Spungin, D., Bonnet, S., Berman-Frank, L., and Hess, W. R.: Global analysis of gene expression dynamics within the marine microbial community during the VAHINE mesocosm experiment in the South West Pacific, Biogeosciences Discuss., doi:10.5194/bg-2015-564, in review, 2016.

Pinhassi, J., Sala, M. M., Havskum, H., Peters, F., Guadayol, O., Malits, A., and Marrasé, C.: Changes in bacterioplankton composition under different phytoplankton regimens, Appl. Environ. Microbiol., 70, 6753-6766, doi:10.1128/AEM.70.11.67536766.2004, 2004.

Pinto, F. L., Thapper, A., Sontheim, W., and Lindblad, P.: Analysis of current and alternative phenol based RNA extraction methodologies for cyanobacteria, BMC Mol. Biol., 10, 79, doi:10.1186/1471-2199-10-79, 2009.

Quast, C., Pruesse, E., Yilmaz, P., Gerken, J., Schweer, T., Yarza, P., Peplies, J., and Glöckner, F. O.: The SILVA ribosomal RNA gene database project: improved data processing and web-based tools, Nucleic Acids Res., 41, D590-596, doi:10.1093/nar/gks1219, 2013.

Riemann, L., Steward, G. F., and Azam, F.: Dynamics of bacterial community composition and activity during a mesocosm diatom bloom, Appl. Environ. Microbiol., 66, 578-587, 2000.

Rognes, T., Mahé, F., Flouri, T., McDonald, D., and Schloss, P.: vsearch: VSEARCH 1.4.0, doi:10.5281/zenodo.31443, 2015.

Sabehi, G., Shaulov, L., Silver, D. H., Yanai, I., Harel, A., and Lindell, D.: A novel lineage of myoviruses infecting cyanobacteria is widespread in the oceans, P. Natl. Acad. Sci. USA, 109, 2037 2042, doi:10.1073/pnas.1115467109, 2012.

Scanlan, D. J., Ostrowski, M., Mazard, S., Dufresne, A., Garczarek, L., Hess, W. R., Post, A. F., Hagemann, M., Paulsen, I., and Partensky, F.: Ecological genomics of marine picocyanobacteria, Microbiol. Mol. Biol. Rev., 73, 249-299, doi:10.1128/MMBR.00035-08, 2009.

Sohm, J. A., Ahlgren, N. A., Thomson, Z. J., Williams, C., Moffett, J. W., Saito, M. A., Webb, E. A., and Rocap, G.: Co-occurring Synechococcus ecotypes occupy four major oceanic regimes defined by temperature, macronutrients and iron, ISME J., 10, 333345, doi:10.1038/ismej.2015.115, 2015.

Spungin, D., Pfreundt, U., Berthelot, H., Bonnet, S., AlRoumi, D., Natale, F., Hess, W. R., Bidle, K. D., and Berman-Frank, I.: Mechanisms of Trichodesmium bloom demise within the New Caledonia Lagoon during the VAHINE mesocosm experiment, Biogeosciences Discuss., doi:10.5194/bg-2015-613, in review, 2016.

Teeling, H., Fuchs, B. M., Becher, D., Klockow, C., Gardebrecht, A., Bennke, C. M., Kassabgy, M., Huang, S., Mann, A. J., 
Waldmann, J., Weber, M., Klindworth, A., Otto, A., Lange, J., Bernhardt, J., Reinsch, C., Hecker, M., Peplies, J., Bockelmann, F. D., Callies, U., Gerdts, G., Wichels, A., Wiltshire, K. H., Glöckner, F. O., Schweder, T., and Amann, R.: Substratecontrolled succession of marine bacterioplankton populations induced by a phytoplankton bloom, Science, 336, 608-611, doi:10.1126/science.1218344, 2012.

Thompson, A. W., Foster, R. A., Krupke, A., Carter, B. J., Musat, N., Vaulot, D., Kuypers, M. M. M., and Zehr, J. P.: Unicellular cyanobacterium symbiotic with a single-celled eukaryotic alga, Science, 337, 1546-1550, doi:10.1126/science.1222700, 2012.

Torréton, J.-P., Rochelle-Newall, E., Pringault, O., Jacquet, S., Faure, V., and Briand, E.: Variability of primary and bacterial production in a coral reef lagoon (New Caledonia), Mar. Pollut. Bull., 61, 335-348, doi:10.1016/j.marpolbul.2010.06.019, 2010.

Tripp, H. J.: The unique metabolism of SAR11 aquatic bacteria, J. Microbiol., 51, 147-153, doi:10.1007/s12275-013-2671-2, 2013.

Tripp, H. J., Bench, S. R., Turk, K. A., Foster, R. A., Desany, B. A., Niazi, F., Affourtit, J. P., and Zehr, J. P.: Metabolic streamlining in an open-ocean nitrogen-fixing cyanobacterium, Nature, 464, 90-94, doi:10.1038/nature08786, 2010.

Turk-Kubo, K. A., Frank, I. E., Hogan, M. E., Desnues, A., Bonnet, S., and Zehr, J. P.: Diazotroph community succession during the VAHINE mesocosm experiment (New Caledonia lagoon), Biogeosciences, 12, 7435-7452, doi:10.5194/bg-12-7435-2015, 2015.

Van Mooy, B. A. S., Rocap, G., Fredricks, H. F., Evans, C. T., and Devol, A. H.: Sulfolipids dramatically decrease phosphorus demand by picocyanobacteria in oligotrophic marine environments, P. Natl. Acad. Sci. USA, 103, 8607-8612, doi:10.1073/pnas.0600540103, 2006.

Van Mooy, B. A. S., Fredricks, H. F., Pedler, B. E., Dyhrman, S. T., Karl, D. M., Koblízek, M., Lomas, M. W., Mincer, T. J., Moore, L. R., Moutin, T., Rappé, M. S., and Webb, E. A.: Phytoplankton in the ocean use non-phosphorus lipids in response to phosphorus scarcity, Nature, 458, 69-72, doi:10.1038/nature07659, 2009.
Veldhuis, M. J. W., Kraay, G. W., Van Bleijswijk, J. D. L., and Baars, M. A.: Seasonal and spatial variability in phytoplankton biomass, productivity and growth in the northwestern Indian Ocean: the southwest and northeast monsoon, 1992-1993, DeepSea Res. Pt. I, 44, 425-449, 1997.

Van Wambeke, F., Pfreundt, U., Barani, A., Berthelot, H., Moutin, T., Rodier, M., Hess, W. R., and Bonnet, S.: Heterotrophic bacterial production and metabolic balance during the VAHINE mesocosm experiment in the New Caledonia lagoon, Biogeosciences Discuss., 12, 19861-19900, doi:10.5194/bgd-12-19861-2015, 2015.

West, N. J., Obernosterer, I., Zemb, O., and Lebaron, P.: Major differences of bacterial diversity and activity inside and outside of a natural iron-fertilized phytoplankton bloom in the Southern Ocean, Environ. Microbiol., 10, 738-756, doi:10.1111/j.14622920.2007.01497.x, 2008.

Wong, M.-T. and Liu, W.-T.: Ecophysiology of Defluviicoccusrelated tetrad-forming organisms in an anaerobic-aerobic activated sludge process, Environ. Microbiol., 9, 1485-1496, doi:10.1111/j.1462-2920.2007.01267.x, 2007.

Wong, M.-T., Tan, F. M., Ng, W. J., and Liu, W.-T.: Identification and occurrence of tetrad-forming Alphaproteobacteria in anaerobic-aerobic activated sludge processes, Microbiology, 150, 3741-3748, doi:10.1099/mic.0.27291-0, 2004.

Yin, Q., Fu, B., Li, B., Shi, X., Inagaki, F., and Zhang, X.-H.: Spatial variations in microbial community composition in surface seawater from the ultra-oligotrophic center to rim of the South Pacific Gyre, PloS One, 8, e55148, doi:10.1371/journal.pone.0055148, 2013.

Zwirglmaier, K., Jardillier, L., Ostrowski, M., Mazard, S., Garczarek, L., Vaulot, D., Not, F., Massana, R., Ulloa, O., and Scanlan, D. J.: Global phylogeography of marine Synechococcus and Prochlorococcus reveals a distinct partitioning of lineages among oceanic biomes, Environ. Microbiol., 10, 147-161, doi:10.1111/j.1462-2920.2007.01440.x, 2008. 